\title{
Experimental study on engineering properties of concrete reinforced with hybrid recycled tyre steel and polypropylene fibres
}

\author{
Hui Zhong , Mingzhong Zhang * \\ Department of Civil, Environmental and Geomatic Engineering, University College London, London, WC1E 6BT, UK
}

\section{A R T I C L E I N F O}

\section{Article history:}

Received 14 November 2019

Received in revised form

3 January 2020

Accepted 3 March 2020

Available online 6 March 2020

Handling editor: Jian Zuo

\section{Keywords:}

Hybrid fibre reinforced concrete

Recycled fibre

Strength

Toughness

Durability

Digital image correlation

\begin{abstract}
A B S T R A C T
Recycled tyre steel fibre (RTSF) is considered as a potential and sustainable alternative to manufactured steel fibre (MSF), while RTSF resulted in lower energy absorption capacity and more serious corrosion problem in concrete compared to MSF. This paper presents an experimental study on engineering properties of concrete reinforced with hybrid RTSF $\left(0.5 \%-0.9 \% \mathrm{~V}_{\mathrm{f}}\right)$ and polypropylene fibre (PPF, $0.1 \%$ $-0.5 \% \mathrm{~V}_{\mathrm{f}}$ ). Results show that combining RTSF with PPF could compensate the serious workability loss caused by RTSF and the workability was improved by $38.9 \%-66.7 \%$. However, the compressive, splitting tensile and flexural strengths were weakened significantly when PPF was over $0.3 \% \mathrm{~V}_{\mathrm{f}}$ in hybrid fibre reinforcement (total content of $1.0 \% \mathrm{~V}_{\mathrm{f}}$ ). The strain field shown in digital image correlation images suggests that hybrid RTSF and PPF can create a synergistic effect in restraining the crack growth and the post-cracking behaviour of concrete especially toughness that was enhanced with the presence of PPF. RTSF was more effective in restraining shrinkage of concrete than PPF. With the increase of PPF content in hybrid fibre reinforcement, the chloride migration coefficient of concrete was reduced by $4.9 \%-6.8 \%$ as compared with the mixture reinforced with only RTSF.
\end{abstract}

๑ 2020 The Authors. Published by Elsevier Ltd. This is an open access article under the CC BY-NC-ND license (http://creativecommons.org/licenses/by-nc-nd/4.0/).

\section{Introduction}

Given the fact that normal concrete is inherently brittle making it unsuitable for certain applications, e.g. structural elements subjected to potential dynamic loadings, fibre reinforced concrete (FRC) incorporating randomly distributed short fibres such as steel, polypropylene and glass fibres is introduced to mitigate the brittleness and potential cracking problem of conventional concrete. Nevertheless, mono fibre reinforcement (i.e. concrete reinforced with only one type of fibre) can only improve either strength or ductility of FRC (Pakravan et al., 2017). For instance, the incorporation of fibres with high modulus and strength such as steel and carbon fibres into concrete can effectively improves its strength while its ductility is not enhanced owing to the brittle nature of the fibres (Pakravan et al., 2017). However, utilizing polymeric fibres such as polypropylene fibre with low strength into concrete can significantly improve its ductility, crack-resistant behaviour and corrosion resistance (Feng et al., 2019; Pakravan and Ozbakkaloglu, 2019). Thus, applying hybrid fibre reinforcement (i.e. concrete

\footnotetext{
* Corresponding author.

E-mail address: mingzhong.zhang@ucl.ac.uk (M. Zhang).
}

reinforced with two or more different types of fibre) in concrete is considered as a promising solution to further improve the mechanical and durability performances of FRC through integrating the function of each reinforced fibre.

Among all the combinations of hybrid short fibre reinforcement in normal concrete, the combination of steel fibre (SF) and polypropylene fibre (PPF) is found to be the most effective one in improving the overall properties of the composite especially strength and ductility. In the past two decades, numerous studies (Afroughsabet et al., 2018; Afroughsabet and Ozbakkaloglu, 2015; Almusallam et al., 2016; Caggiano et al., 2016; de Alencar Monteiro et al., 2018; Feng et al., 2019; Li et al., 2018; Li et al., 2019a; Li et al., 2019b; Qian and Stroeven, 2000; Suhaendi and Horiguchi, 2006; Sun et al., 2001; Yao et al., 2003; Yermak et al., 2017) investigated the effect of hybrid SF and PPF with the total fibre volume fraction $\left(V_{f}\right)$ of $0.5-3.6 \%$ on the mechanical properties and durability of FRC. For instance, Yao et al. (2003) examined the mechanical properties of concrete reinforced with hybrid hooked-end SF and PPF at the fibre dosage of $0.5 \% \mathrm{~V}_{\mathrm{f}}$ and found that the incorporation of hybrid $\mathrm{SF}$ and PPF could create a synergetic effect in improving both strength and ductility of FRC as compared with the plain mixture, which is in agreement with de Alencar Monteiro et al. (2018) and Li et al. (2018) that both peak and post-peak behaviour of concrete 
reinforced with appropriate dosages of SF and PPF were significantly enhanced. It was also found that the utilization of both SF and PPF into concrete prevents it from spalling under fire attack mainly owing to the increased permeability (Li et al., 2019a, 2019b). However, a huge amount of raw materials (e.g. fossil fuel) and energy is required to produce the aforementioned fibres (Mastali et al., 2018a, 2018b; Onuaguluchi and Banthia, 2018), where the cost of the resultant composite increases with the reduction of sustainability, i.e. inevitable greenhouse gas emissions during the production of steel (Liew and Akbar, 2020). To mitigate the environmental issues and threat of natural resource shortage, an increasing number of studies have been carried out to utilize the recycled materials as the reinforcing fibre for concrete and among them, recycling the materials from the end-of-life tyres, e.g. steel and polymeric fibres to replace the manufactured fibres is one of the most recent attempts.

It was reported that more than 500 million waste tyres are landfilled (Thomas and Gupta, 2016) while limited land disposal sites would become one of the serious threats to human society (Wang et al., 2019). The accumulated solid tyre waste could also pose several challenges to the environment as it may induce fire or disease (Ramarad et al., 2015; Zhong et al., 2019). However, through certain processing stages, rubber particles, steel and polymer fibres can be recovered (Gigli et al., 2019), which provides a potential way to effectively recycle a majority of waste tyres around the world. It is worth noting that steel is a major component of a tyre which accounts for around 13\%-27\% (Ramarad et al., 2015), implying that the effective usage of recycled tyre steel materials could significantly mitigate the potential problems caused by the waste tyres. For instance, recycling of waste tyres could stop around 1.52 tons of $\mathrm{CO}_{2}$ emissions yearly (Liew and Akbar, 2020). Up to now, many studies (Aiello et al., 2009; Centonze et al., 2012; Frazão et al., 2019; Grzymski et al., 2019; Leone et al., 2018; Skarżyński and Suchorzewski, 2018; Zamanzadeh et al., 2015) examined the effect of recycled tyre steel fibre (RTSF) content on the physical, mechanical and durability properties of FRC with a primary aim of seeking whether the manufactured steel fibre (MSF) could be replaced by RTSF. The majority of the studies indicated that the flexural behaviour particularly post-cracking performance of concrete reinforced with RTSF was comparable to that reinforced with MSF considering certain fibre content. Nevertheless, Skarżyński and Suchorzewski (2018) concluded that concrete mixture reinforced with RTSF exhibited poorer properties compared to that reinforced with MSF under the same fibre volume fraction because of the irregular dimension of RTSF. Grzymski et al. (2019) reported similar observation that the inclusion of RTSF led to the reduced energy absorption capacity of FRC after cracking in comparison with the addition of MSF, suggesting that the use of RTSF with an appropriate content in normal concrete is essential. On the other hand, an increasing number of studies (Bjegovic et al., 2014; Caggiano et al., 2017; Hu et al., 2018; Martinelli et al., 2015; Mastali et al., 2018a, 2018b; Onuaguluchi and Banthia, 2018) focused on the overall properties of concrete reinforced with hybrid MSF and RTSF, which found that partial replacement of MSF by RTSF could create synergistic effects leading to the improvements in tensile strength, ductility and impact resistance whereas the properties of the resultant FRC were negatively influenced when the content of RTSF was excessive. Frazão et al. (2019) concluded that RTSF was more susceptible to corrosion than MSF, which may hinder the application of RTSF-FRC in aggressive environment, e.g. marine. It was reported that PPF has better performance to resist corrosion and improve the ductility. Thus, integrating PPF with RTSF has potential to mitigate the aforementioned issues drawn by RTSF while maintaining the benefits induced by RTSF, e.g. strength. To the best of the authors' knowledge, only one relevant study (Mastali et al., 2018a) evaluated the effect of hybrid RTSF and PPF on the mechanical properties of self-consolidating concrete with the total fibre content of $1.5 \% V_{f}$. However, through assessing the effects of three different hybrid combinations, i.e. $0.5 \% V_{f}$ of PPF $+1.0 \% V_{f}$ of RTSF, $0.75 \% V_{f}$ of PPF $+0.75 \% V_{f}$ of RTSF, and $1.0 \% V_{f}$ of PPF $+0.5 \% V_{f}$ of RTSF, it was observed that excessive content of PPF weakened the mechanical properties of FRC mainly due to the weak bonding between fibre and matrix (Mastali et al., 2018a), implying that PPF was not suitable to be used as primary fibre in hybrid fibre reinforcement, i.e. accounting for the major part of hybrid system. However, durability-related properties (e.g. resistance to chloride migration) were not assessed and more different hybrid combinations are required. In order to further investigate the feasibility of combining RTSF as sustainable material with synthetic PPF in concrete, it is vital to conduct an extensive research on the effect of more hybrid combinations (i.e. RTSF as primary fibre) on the engineering properties of concrete.

The main purpose of this study is to provide a comprehensive understanding of the effect of hybrid RTSF and PPF on the engineering properties of concrete considering five hybrid combinations with a total fibre content of $1.0 \% \mathrm{~V}_{\mathrm{f}}$. Concrete mixtures without fibre reinforcement and reinforced with $1.0 \% V_{f}$ were considered as the reference mixtures. Firstly, a series of tests were carried out to estimate the effects of mono and hybrid fibre reinforcements on the workability, compressive strength, flexural behaviour and drying shrinkage of concrete. The evolution of full strain field under different loading levels and flexural failure of studied mixtures were explored using a non-contact measurement, i.e. digital image correlation (DIC). The interaction between fibre and matrix at the cracking zone was then observed using a digital microscope. Finally, rapid chloride migration (RCM) test was conducted to estimate the effect of different hybrid fibre reinforcements on the durability-related performance of concrete.

\section{Experimental programme}

\subsection{Raw materials}

CEM I $52.5 \mathrm{~N}$ Portland cement was used as the main binder material in this study, the fineness of which was $366 \mathrm{~m}^{2} / \mathrm{kg}$ and its chemical composition is listed in Table 1. Fine and coarse aggregates were Thames valley sand and crushed granites, respectively, which were used in saturated surface dry (SSD) condition whilst mixing. Modified polycarboxylate-based superplasticisers were used to improve the fluidity of mixtures, where the content was set as $0.55 \%$ by the mass of cement content. RTSF (see Fig. $1 \mathrm{a}$ and b) (Zhong et al., 2019) and PPF (see Fig. 1c and d) were used as reinforcing fibres in this study. The properties of RTSF and PPF are presented in Table 2 .

\subsection{Mixture proportions and specimen preparation}

Table 3 shows the designated mix proportions of all mixtures that had a fixed water-to-binder (w/b) ratio of 0.40 . In total, six FRC mixtures were proposed here. Five hybrid fibre reinforced mixtures were studied with the total fibre content of $1.0 \% \mathrm{~V}_{\mathrm{f}}$, where the fibre volume fraction of RTSF and PPF was $0.5 \%-0.9 \%$ and $0.1 \%-0.5 \%$, respectively. Mixtures without fibre incorporation (i.e. F0) and with

Table 1

Chemical compositions (wt\%) of Portland cement (PC)

\begin{tabular}{llllllllll}
\hline Oxide & $\mathrm{SiO}_{2}$ & $\mathrm{Al}_{2} \mathrm{O}_{3}$ & $\mathrm{Fe}_{2} \mathrm{O}_{3}$ & $\mathrm{~K}_{2} \mathrm{O}$ & $\mathrm{CaO}$ & $\mathrm{MgO}$ & $\mathrm{Na}_{2} \mathrm{O}$ & $\mathrm{SO}_{3}$ & LOI \\
\hline $\mathrm{PC}$ & 20.18 & 4.87 & 3.23 & 0.68 & 63.35 & 1.09 & 0.13 & 2.96 & 1.64 \\
\hline
\end{tabular}


(a)
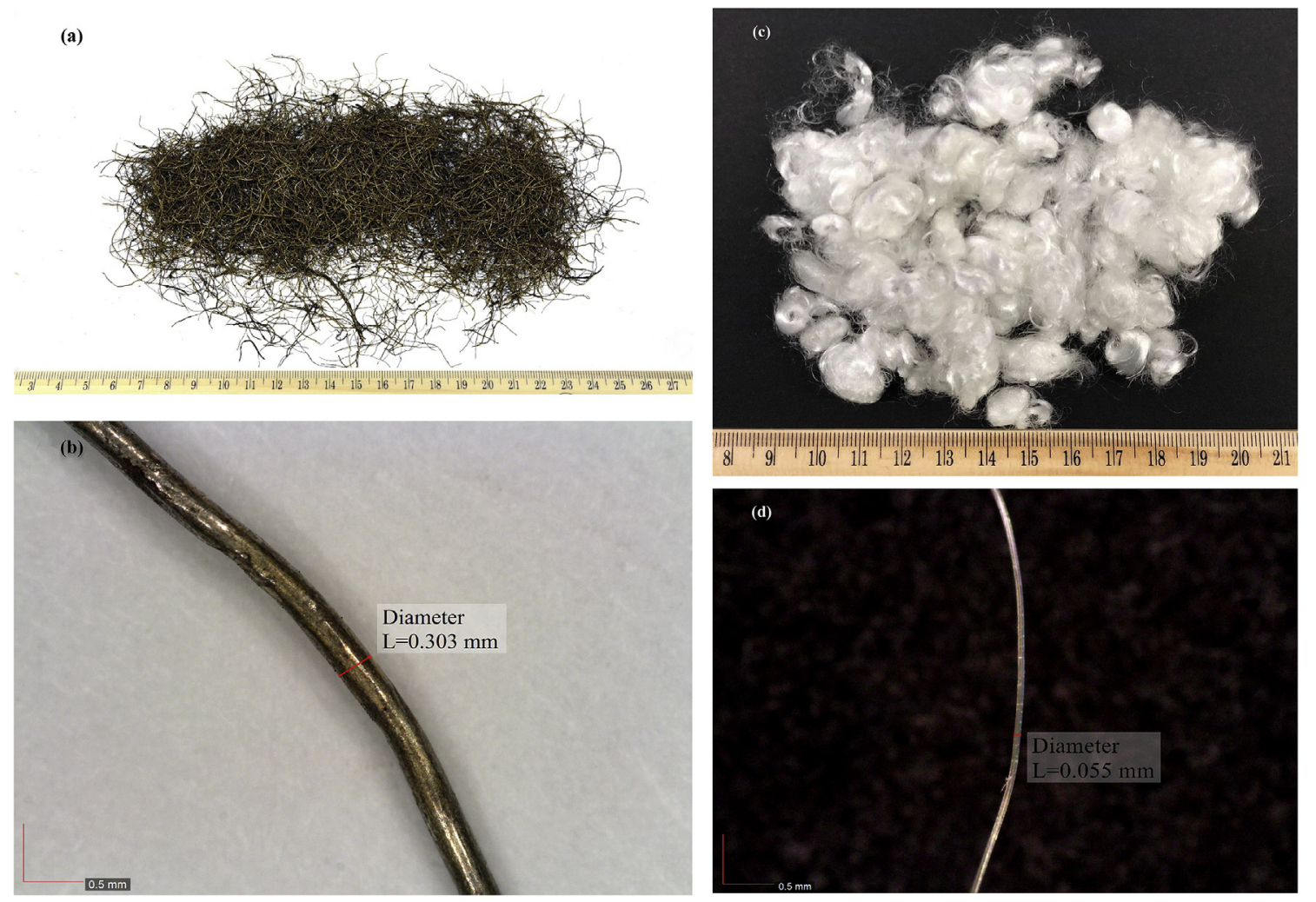

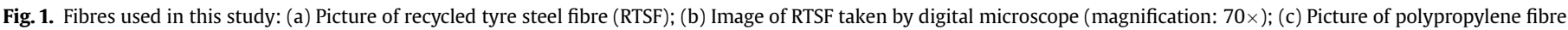
(PPF); (d) Image of PPF taken by digital microscope (magnification: 70×).

Table 2

Properties of fibres used in this study.

\begin{tabular}{|c|c|c|c|c|c|}
\hline Fibre type & Length (mm) & Diameter $(\mu \mathrm{m})$ & Aspect ratio & Tensile strength (MPa) & Elastic modulus (GPa) \\
\hline RTSF & $23 *$ & $220 *$ & $100 *$ & 2570 & 200 \\
\hline PPF & 12 & $50 *$ & $240 *$ & 380 & 1 \\
\hline
\end{tabular}

Note: *(Nominal value); RTSF (recycled tyre steel fibre); PPF (polypropylene fibre).

$1.0 \% V_{f}$ of RTSF (i.e. RS1.0) were considered as reference mixtures. With respect to the symbol shown in Table 3, 'F', 'RS' and 'PP' represents fibre, recycled steel and polypropylene, respectively. The denoted number (e.g. 1.0 and 0.9 ) is the corresponding fibre content. For instance, RS0.9PP0.1 denotes the FRC incorporating $0.9 \% \mathrm{~V}_{\mathrm{f}}$ of RTSF and $0.1 \% \mathrm{~V}_{\mathrm{f}}$ of PPF.

Fig. 2 shows the adopted mixing procedure for both plain and FRC mixtures. After mixing, fresh mixtures were poured into different steel moulds and then covered by a polyethene sheet for avoiding excessive water evaporation. After $24 \mathrm{~h}$, all specimens were de-moulded and cured in water tank with a temperature of
$20{ }^{\circ} \mathrm{C}$, except the samples used for drying shrinkage test.

\subsection{Testing methods}

\subsubsection{Workability}

Slump test was conducted to determine the workability of all mixtures according to ASTM 143-15a (2015). The slump is interpreted as the vertical displacement between the top of the mould and the centre of the top surface of the sample.

Table 3

Mixture proportions.

\begin{tabular}{|c|c|c|c|c|c|c|c|}
\hline No (Symbol) & Cement $\left(\mathrm{kg} / \mathrm{m}^{3}\right)$ & $\mathrm{FA}\left(\mathrm{kg} / \mathrm{m}^{3}\right)$ & $\mathrm{CA}\left(\mathrm{kg} / \mathrm{m}^{3}\right)$ & Water $\left(\mathrm{kg} / \mathrm{m}^{3}\right)$ & $\operatorname{SPs}\left(\mathrm{kg} / \mathrm{m}^{3}\right)$ & RTSF (vol\%) & PPF (vol\%) \\
\hline M1(F0) & 490 & 694 & 1040 & 196 & 2.695 & 0 & 0 \\
\hline M2 (RS1.0) & 490 & 694 & 1040 & 196 & 2.695 & 1.0 & 0 \\
\hline M3 (RS0.9PP0.1) & 490 & 694 & 1040 & 196 & 2.695 & 0.9 & 0.1 \\
\hline M4 (RS0.8PP0.2) & 490 & 694 & 1040 & 196 & 2.695 & 0.8 & 0.2 \\
\hline M5 (RS0.7PP0.3) & 490 & 694 & 1040 & 196 & 2.695 & 0.7 & 0.3 \\
\hline M6 (RS0.6PP0.4) & 490 & 694 & 1040 & 196 & 2.695 & 0.6 & 0.4 \\
\hline M7 (RS0.5PP0.5) & 490 & 694 & 1040 & 196 & 2.695 & 0.5 & 0.5 \\
\hline
\end{tabular}

Note: FA (fine aggregate); CA (coarse aggregate); SPs (superplasticisers). 


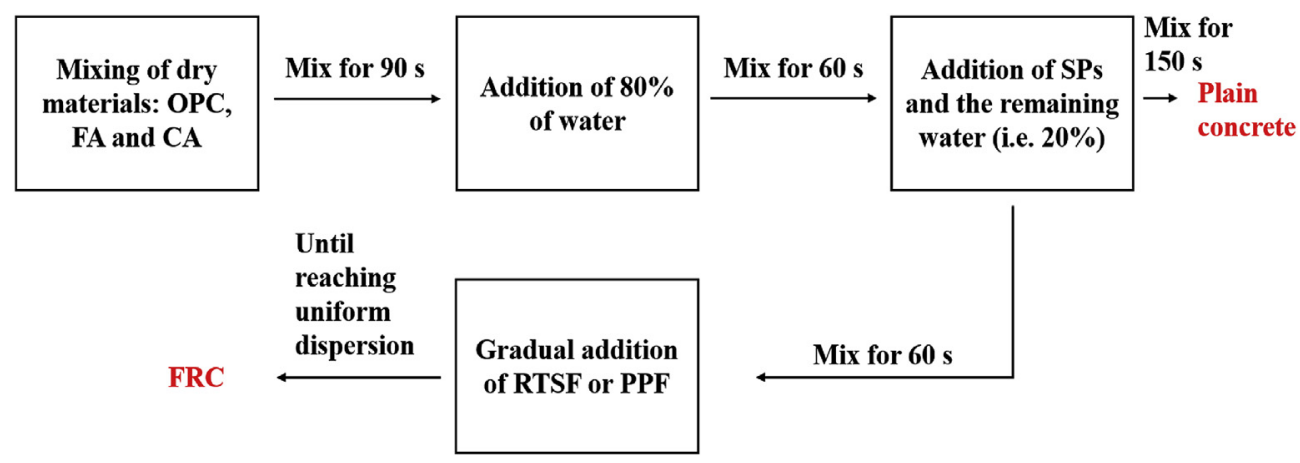

Fig. 2. Mixing procedure for plain concrete and fibre reinforced concrete (FRC).

\subsubsection{Compressive strength}

In accordance with BS EN 12390-3 (2009), the compressive strength of each mixture was evaluated by a universal testing machine using $100 \mathrm{~mm}$ cubes at the testing ages of 7, 28 and $56 \mathrm{~d}$.

\subsubsection{Splitting tensile strength}

Following ASTM C496 (2011), the splitting tensile strength test was performed on three cylindrical specimens (i.e. $100 \mathrm{~mm}$ diameter with a height of $200 \mathrm{~mm}$ ) at $28 \mathrm{~d}$.

\subsubsection{Flexural behaviour}

Four-point bending tests on three prismatic samples $(100 \times 100 \times 500 \mathrm{~mm})$ at $28 \mathrm{~d}$ were conducted as per ASTM C1018 (1997) to determine the flexural behaviour of all mixtures, where the previous work (Zhong et al., 2019) found that this standard was more suitable for describing the flexural behaviour of FRC with deflection-hardening feature. A controlled displacement rate of $1 \mathrm{~mm} / \mathrm{min}$ was adopted for all flexural testing in this study.

Three-dimensional DIC system was used to evaluate the crack propagation and full strain field of the tested concrete in this study. The main setup of DIC test is shown in Fig. 3. As seen in Fig. 3a, two cameras (Imager M-lite 5M CMOS) with a resolution of 2464 x 2056 pixels and a focal length of $35 \mathrm{~mm}$ were adopted for capturing the images whilst flexural testing with an image rate of $1 \mathrm{~Hz}$, i.e. one image per second. The received data was processed in software called 'StrainMaster' as shown in Fig. 3d. With respect to the preparation of the tested specimen, a random speckle pattern (i.e. white paint as the base with randomly distributed black dots on the top) was made on its surface (see Fig. 3b). A calibration test was conducted prior to the DIC measurement. Regarding the accuracy of displacement on a point-to-point basis for translational movements, the residual fit error was in the range of $0.025-0.05$ pixel. For the calculation processed in 'StrainMaster', the subset size was adjusted as 60 pixels with the aim of covering around 3 to 5 speckle patterns in each subset. In addition, the correlation mode was set as 'Relative to first'. Finally, the full transverse strain field of each mixture whilst the entire flexural loading was accordingly evaluated. By considering the full strain field under different loading levels, the crack propagation of each mixture was attained.

Flexural parameters including toughness indices $\left(I_{5}, I_{10}\right.$ and $\left.I_{20}\right)$ and residual strength factors $\left(R_{5,10}\right.$ and $\left.R_{10,20}\right)$ were derived from the load-deflection curve based on ASTM C1018 (1997).

\subsubsection{Drying shrinkage}

The drying shrinkage of all mixtures was evaluated according to ASTM C490 (2017). Fresh samples without coarse aggregates were poured into the mould with the size of $50 \times 50 \times 285 \mathrm{~mm}$. After demoulding, the original length of each specimen was immediately recorded using a comparator with an accuracy of $0.01 \mathrm{~mm}$.
Thereafter, all specimens were exposed to the environment with a temperature of $20 \pm 2{ }^{\circ} \mathrm{C}$ and a relative humidity (RH) of $55 \pm 5 \%$. The length of each specimen at various curing ages was measured to determine the drying shrinkage.

\subsubsection{Rapid chloride migration test}

RCM test mainly consists of three stages. Before the first stage, the cylindrical sample with a diameter of $100 \mathrm{~mm}$ and a height of $200 \mathrm{~mm}$ was sawed into smaller pieces with a height of $50 \mathrm{~mm}$ as the tested sample. The first stage involves the preconditioning of the tested sample. The specimens were placed in a vacuum desiccator for $3 \mathrm{~h}$. After that, with the vacuum pump still running, the calcium hydroxide $\left(\mathrm{Ca}(\mathrm{OH})_{2}\right)$ solution was added into the vacuum desiccator to fully immerse the specimens and then continue the vacuum treatment for another $1 \mathrm{~h}$ (see Fig. 4a) before allowing the air re-enter the vacuum desiccator. Thereafter, the specimens were maintained in the vacuum for another $18 \pm 2 \mathrm{~h}$ before the test. In the second stage (see Fig. 4b), the specimens were fit into the rubber sleeves and were then secured with 2 clamps. Afterwards, the specimens were exposed to anolyte solution, i.e. $0.3 \mathrm{M}$ sodium hydroxide $(\mathrm{NaOH})$, and placed on top of a plastic support inside the container filled with $10 \%$ sodium chloride $(\mathrm{NaCl})$ as catholyte solution. The voltage on the power supply was set to $30 \mathrm{~V}$ and the initial current was recorded. The initial temperature in each anolyte solution was measured using a thermometer. The test duration and the next voltage were evaluated based on the value of initial current. Herein, the new voltage was the value which was applied to force the chloride ions to penetrate the specimen. Finally, the specimens were split into half and the one with a smoother surface was sprayed by $0.1 \mathrm{M}$ silver nitrate $\left(\mathrm{AgNO}_{3}\right)$. Thereafter, the penetration depth was accordingly measured. As per NT BUILD 492 (1999), the chloride migration coefficient was determined as:

$D_{n s s m}=\frac{0.0239(273+T) L_{t}}{(U-2) t}\left(L_{p}-0.0238 \sqrt{\frac{(273+T) L_{t} L_{p}}{U-2}}\right)$

where $D_{\text {nssm }}$ is the non-steady-state migration coefficient $\left(\times 10^{-12} \mathrm{~m}^{2} / \mathrm{s}\right), U$ is the absolute value of the applied voltage $(\mathrm{V}), T$ is the average initial and final temperature in anolyte solution $\left({ }^{\circ} \mathrm{C}\right), t$ is the test duration (h), $L_{t}$ is the thickness of the tested sample (50 $\mathrm{mm})$, and $L_{p}$ is the average penetration depth ( $\left.\mathrm{mm}\right)$.

\section{Results and discussion}

\subsection{Workability}

Fig. 5 shows the slump of all mixtures that corresponds to the workability of concrete. It can be observed that the addition of 


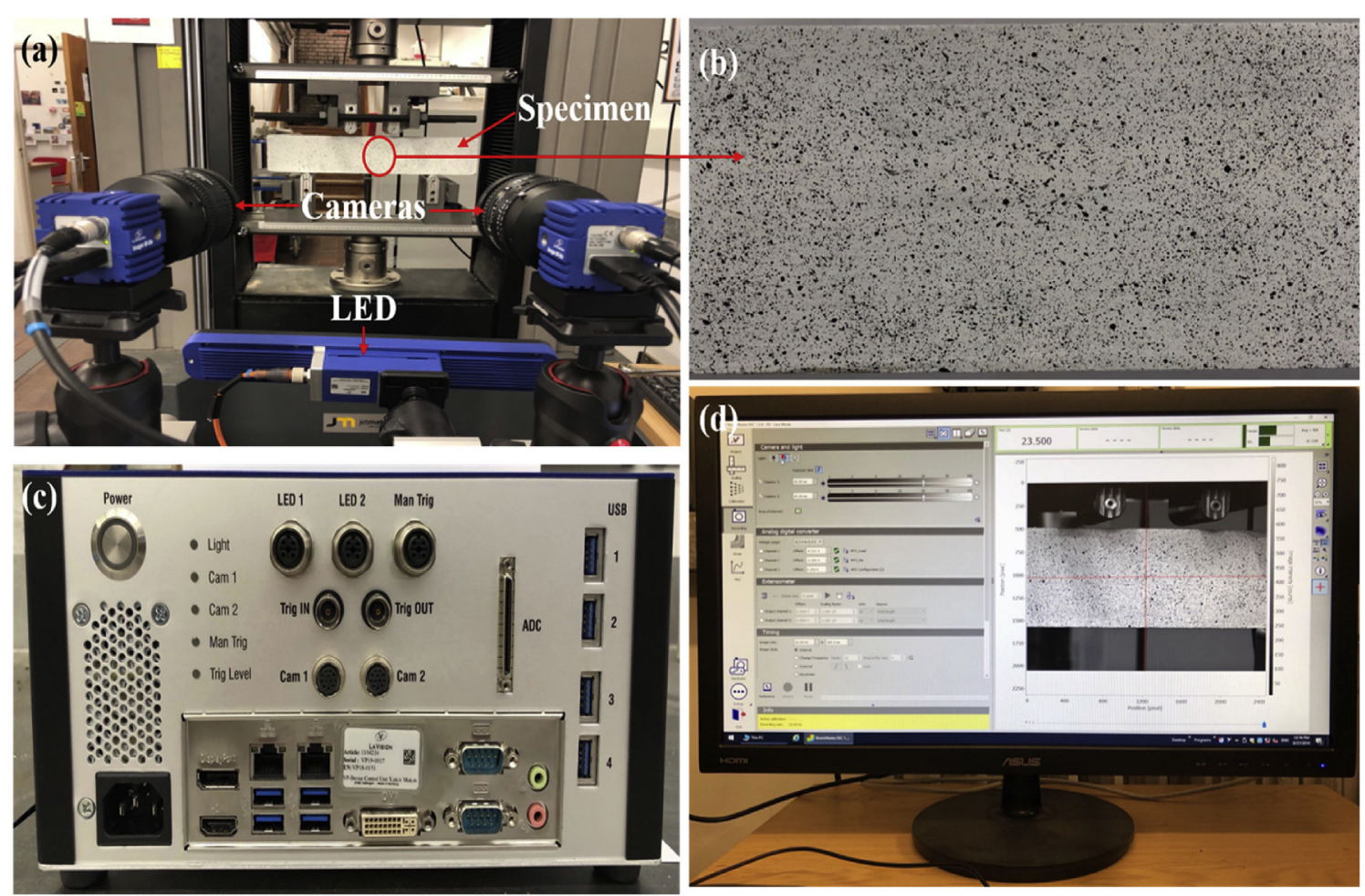

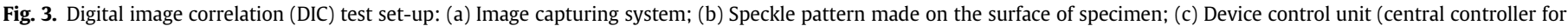
the measurement system); (d) Data processing software (StrainMaster).
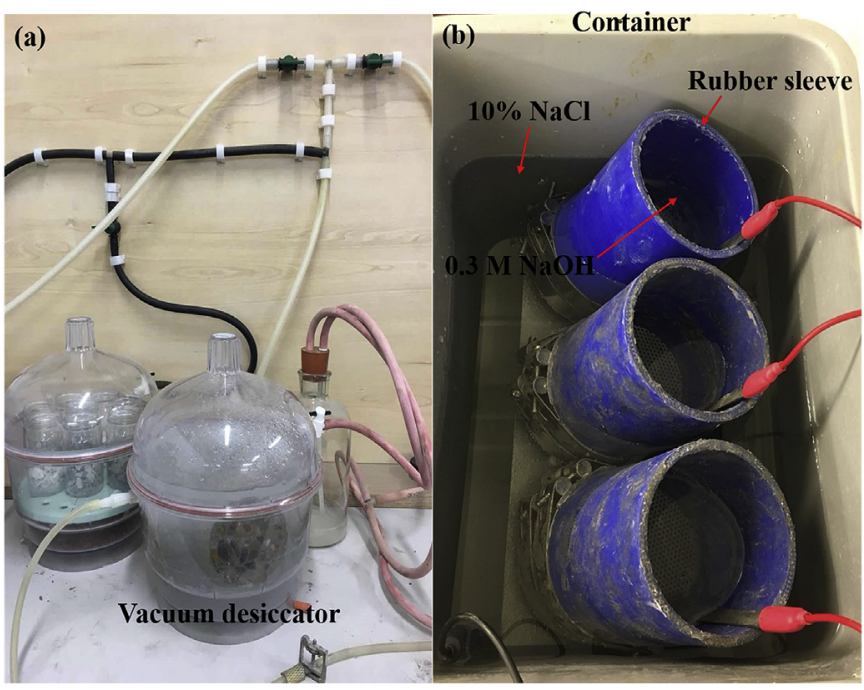

Fig. 4. Main equipment used for rapid chloride migration (RCM) test.

fibres reduced the slump of concrete independent of fibre reinforcement type (mono or hybrid). RS1.0 presented a slump of only $90 \mathrm{~mm}$, which was around 59.1\% lower than that of concrete without fibre incorporation (F0). The reduction in workability caused by either RTSF or PPF incorporation agreed well with previous studies on RTSF (Centonze et al., 2012; Baricevic et al., 2017) and PPF (Yap et al., 2013; Mazzoli et al., 2015) that the addition of fibres increased the shear resistance of fresh concrete mixture to flow owing to the contact mechanism between fibre and matrix resulting in a reduction in concrete flowability (Grünewald, 2012). The workability of FRC could be influenced by various factors

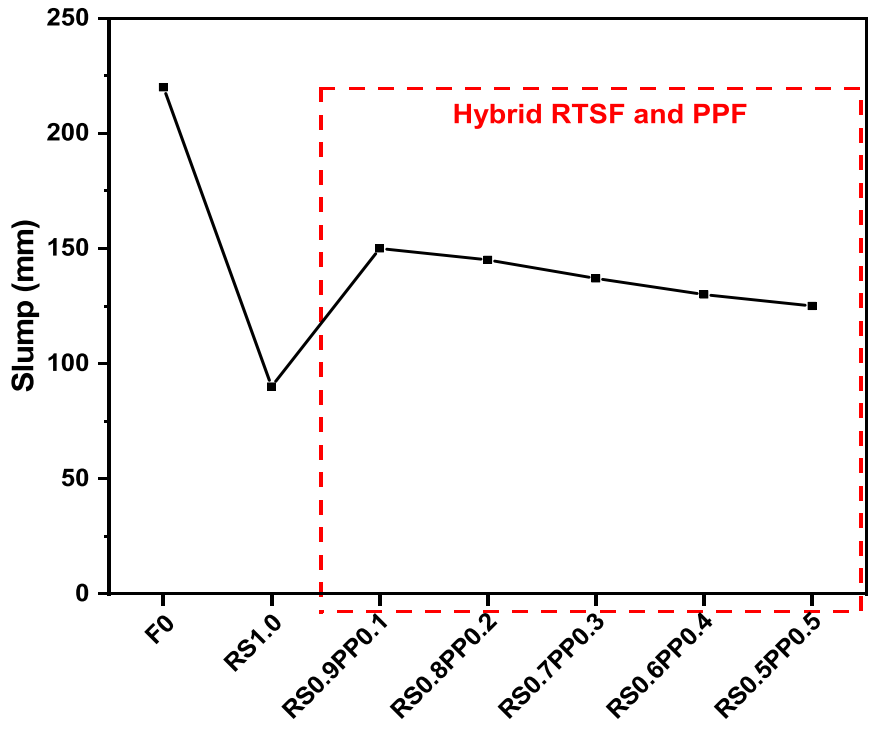

Fig. 5. Effect of fibres on slump of concrete.

including fibre shape, surface area of fibre, fibre aspect ratio and fibre dosage (Pakravan and Ozbakkaloglu, 2019; Ranjbar and Zhang, 2020). The geometry of RTSF shown in Fig. 1a is not uniform, which may intensify the contact network between fibre and matrix. Thus, a more significant reduction in workability may be observed for concrete reinforced with RTSF. In addition, the workability of FRC can be also affected by the critical fibre content, while this value varies between different fibres (e.g. reduced with increasing fibre aspect ratio) (Ranjbar and Zhang, 2020). When the fibre dosage exceeds this critical value, the possibility of fibre clamping or 
balling could be enhanced leading to uneven fibre distribution and more pronounced reduction of flowability (Ranjbar and Zhang, 2020). As seen in Fig. 5, replacing RTSF by $0.1 \% V_{f}$ of PPF led to an increased slump by around 66.7\%, as compared with RS1.0. However, further replacement of RTSF by PPF weakened the positive influence in workability (i.e. decreased by approximately $3.33 \%-$ $16.7 \%$ when the content of PPF was increased from $0.1 \%$ to $0.5 \% V_{f}$, as compared with RS0.9PP0.1). Afroughsabet et al. (2018) observed a similar phenomenon that replacing MSF by $0.15 \%-0.3 \% \mathrm{~V}_{\mathrm{f}}$ of PPF enhanced the workability of FRC compared to that reinforced with mono MSF, whereas further replacement (e.g. $0.45 \% V_{f}$ ) reduced the slump by around $37.5 \%$. This may imply that considering the workability, $0.1 \%-0.2 \% \mathrm{~V}_{\mathrm{f}}$ can be regarded as the critical PPF content in this study. It can be still suggested that the hybrid combination of RTSF and PPF could compensate the workability loss caused by RTSF, as the workability of RS0.5PP0.5 was still around $38.9 \%$ higher than that of RS1.0.

\subsection{Compressive and splitting tensile strength}

Fig. 6 shows the effect of fibres on the compressive strength of concrete at 7, 28 and $56 \mathrm{~d}$. Apart from the mixtures reinforced with only RTSF (RS1.0), the hybrid combination of RTSF and PPF weakened the compressive strength compared to the mixture without fibre inclusion (F0). The addition of fibres could result in either enhancement or reduction in compressive strength of plain concrete, which can be attributed to the different effects caused by the fibres, e.g. crack arresting, increased air voids, etc. (Mastali et al., 2018a). As seen in Fig. 6, the compressive strength of RS1.0 was improved by $4.05 \%-8.19 \%$ at various curing ages in comparison with that of F0 suggesting that RTSF did not induce significant improvement in compressive strength of concrete, which is consistent with the findings by Ahmadi et al. (2017) and Sengul (2016). Additionally, increasing the PPF dosage from $0.1 \%$ to $0.5 \%$ $\mathrm{V}_{\mathrm{f}}$ in hybrid combination, the compressive strength was decreased by approximately $1.22 \%-38.7 \%$ as compared with F0. Similar results were reported in previous studies (Afroughsabet et al., 2018; Afroughsabet and Ozbakkaloglu, 2015; Feng et al., 2019; Mastali et al., 2018a) that the compressive strength was reduced with the increasing PPF dosage $\left(0.15 \%-1.5 \% \mathrm{~V}_{\mathrm{f}}\right)$ in hybrid MSF/RTSF and PPF reinforcement. This can be mainly caused by the poorer fibre

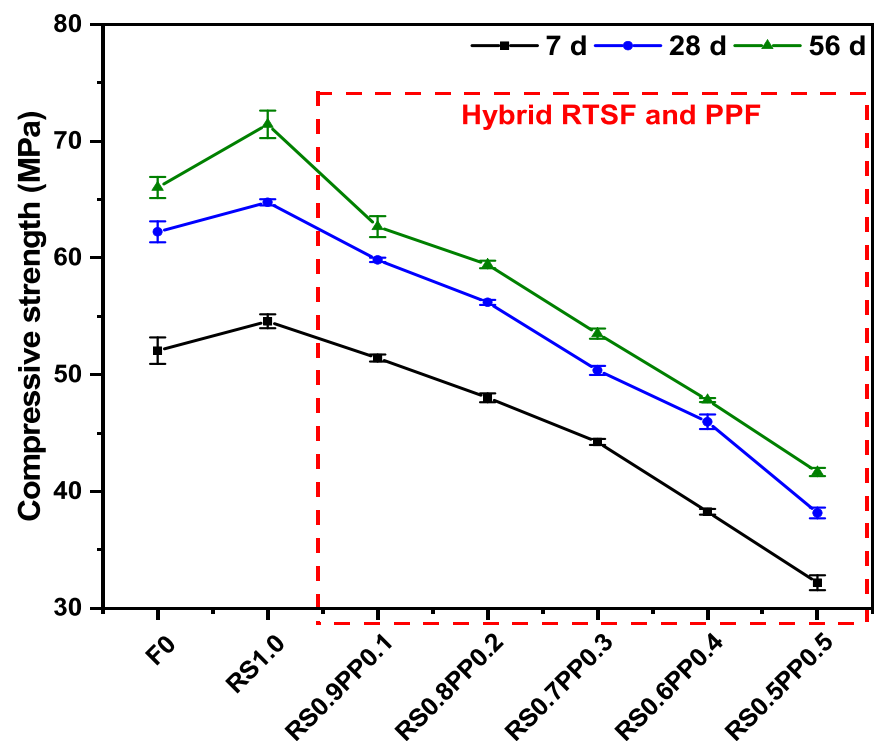

Fig. 6. Effect of fibres on compressive strength of concrete. dispersion that may lead to fibre agglomeration when the critical fibre concentration dosage is exceeded as well as increased porosity and decreased compactness within the internal structure of concrete (see Section 3.1). Thus, the local fractures can be more easily formed near the fibres as the local fractures easily appear near the pores of micro cracks (Ranjbar et al., 2016), leading to the reduced compressive strength of FRC (Ranjbar and Zhang, 2020). However, RS0.9PP0.1 exhibited comparable compressive strength to that of F0 (i.e. no more than $3.87 \%$ difference at $28 \mathrm{~d}$ ), which implies that adding an appropriate content of PPF in hybrid fibre combination would not significantly affect the compressive strength of concrete.

Fig. 7 shows the effect of fibres on the splitting tensile strength of concrete at $28 \mathrm{~d}$. Similar to the results of compressive strength, mixture reinforced with $1.0 \% \mathrm{~V}_{\mathrm{f}}$ of RTSF (RS1.0) achieved the highest splitting tensile strength of around 7.3 $\mathrm{MPa}$, which was over $100 \%$ higher than that of mixture without fibre addition (F0). Previous studies (Ahmadi et al., 2017; Mastali et al., 2018a, 2018b) indicated that the splitting tensile strength of FRC containing RTSF $\left(1.0 \%-1.5 \% V_{f}\right)$ was increased by about $66.7 \%$ at $28 \mathrm{~d}$, which can be mainly attributed to the high efficiency of fibres in bridging the diametric splitting crack (Sivakumar and Santhanam, 2007). In contrast, as observed in Fig. 7, the hybrid usage of RTSF and PPF in concrete showed lower splitting tensile strength in comparison with mono RTSF reinforcement in concrete (i.e. approximately $32.2 \%-62.5 \%$ lower), which shows good agreement with previous studies (Afroughsabet and Ozbakkaloglu, 2015; Mastali et al., 2018a; Yao et al., 2003) that RTSF or MSF presented higher efficiency than PPF in bridging the crack under splitting tensile loading. Despite the increased porosity and reduced integrity of the composite containing PPF, it is worth noting that PPF normally exhibits hydrophobic characteristics and is difficult to be strongly adhered to cementitious materials (Pakravan and Ozbakkaloglu, 2019). Thus, the interfacial bonding between PPF and matrix would be lower than that between RTSF and matrix. When the cracks initiate within concrete, the PPF with relatively lower stiffness could arrest and restrain the micro-crack, while the slippage or de-bonding of PPF may occur as the crack propagates resulting in the reduced load-carrying capacity of the whole composite. However, the addition of PPF up to $0.2 \% V_{f}$ in hybrid fibre reinforcement resulted in better splitting tensile strength as compared with F0 (i.e. around $15.7 \%-36.7 \%$ higher), while further addition of PPF led to

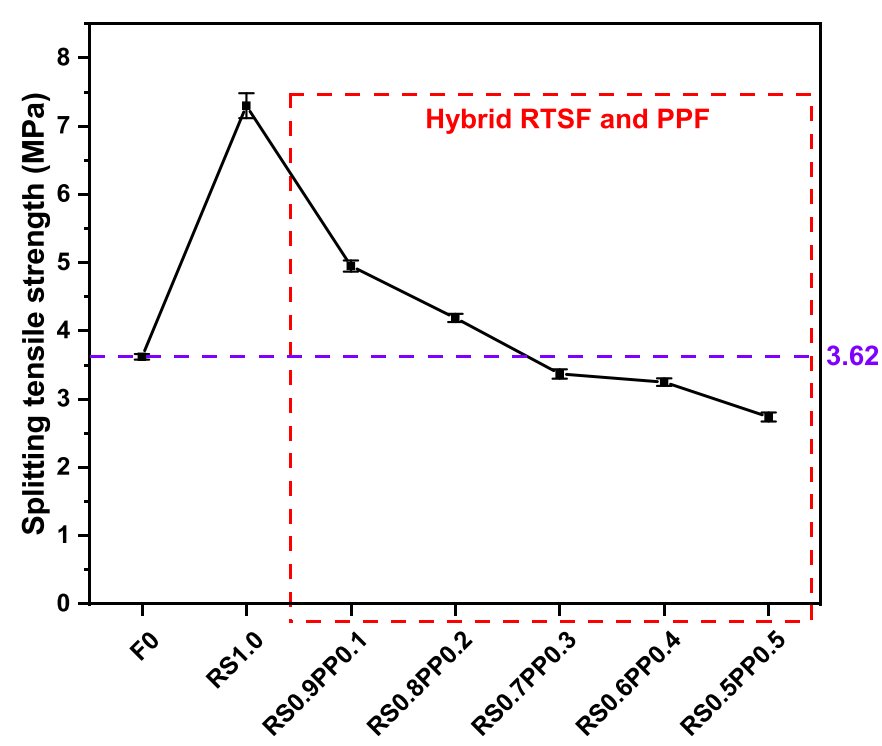

Fig. 7. Effect of fibres on splitting tensile strength of concrete. 
reduction in splitting tensile strength. This implies that $0.2 \% \mathrm{~V}_{\mathrm{f}}$ can be considered as the upper limit of PPF content in the usage of hybrid RTSF and PPF reinforcement if solely considering splitting tensile strength.

\subsection{Flexural behaviour}

\subsubsection{Load-deflection behaviour}

A typical load-deflection curve of FRC is shown in Fig. 8, where the end point of the linearity (point A) was referred to as the firstpeak load while the flexural strength was calculated based on the peak load (point B). Unlike plain concrete, FRC may exhibit deflection-hardening response and can sustain further loading after cracking occurs. With certain type of fibre reinforcement (e.g. PPF), FRC may also present deflection-softening feature pointing out the improvement in ductility in comparison with the plain concrete.

Fig. 9 illustrates the load-deflection relationships of all mixtures. It can be clearly seen that plain concrete (F0) failed immediately after reaching the elastic limit point (point A or B in Fig. 8) at around $0.799 \mathrm{~mm}$, while all FRCs exhibited similar responses as that shown in Fig. 8. However, reinforcing the concrete with fibres did not induce a pronounced improvement in first-crack load as it is mainly influenced by the matrix strength (Niu et al., 2019). The flexural strength determined based on point B in Fig. 8 is presented in Fig. 10. Considering the fibre effect on the flexural strength, RTSF was effective in enhancing the flexural strength of concrete matrix (i.e. increased by about $116.8 \%$ when the concrete reinforced with $1.0 \% V_{f}$ of RTSF), which showed well agreement with previous studies (Ahmadi et al., 2017; Hu et al., 2018; Mastali et al., 2018a). This was also in consistence with previous discussion on splitting tensile strength that RTSF was more efficient in sustaining the load in the presence of cracks. As observed in Fig. 10, partially replacing RTSF with PPF from $0.1 \%$ to $0.3 \% \mathrm{~V}_{\mathrm{f}}$ in concrete showed comparable flexural strength to that of F0 (i.e. no more than 5.26\% difference), while further replacement induced greater reduction (up to about $21.7 \%$ ) in flexural strength. As explained previously, the reasons causing this reduction can be associated with the properties and surface condition of PPF, where greater use of PPF could increase the porosity of FRC and reduce its integrity (i.e. especially when the fibre concentration dosage is exceeded). The weak interaction with the cementitious matrix led to the reduced load-carrying capacity of the whole composite, but the slippage and de-bonding of the PPF

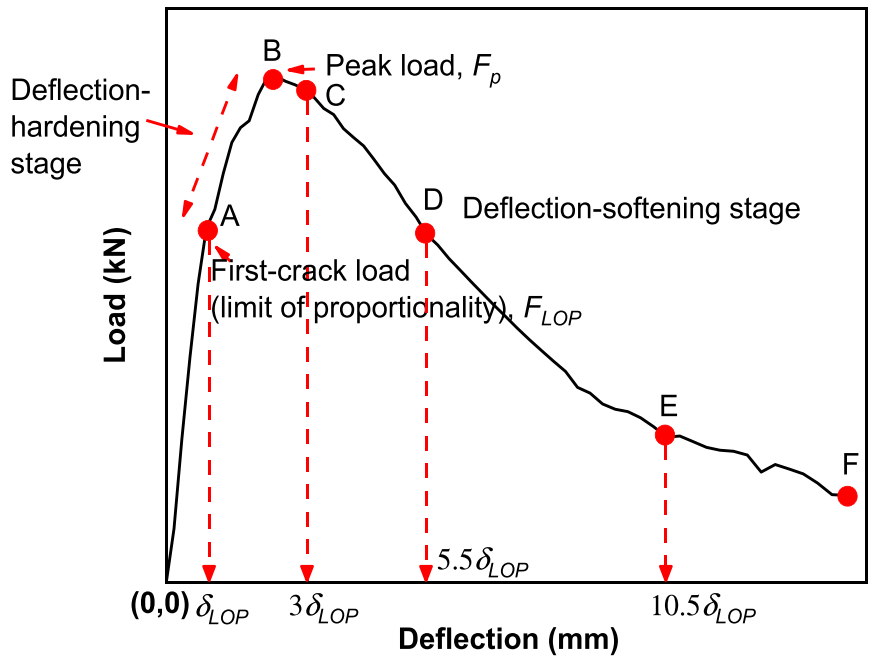

Fig. 8. Typical load-deflection curve of fibre reinforced concrete.

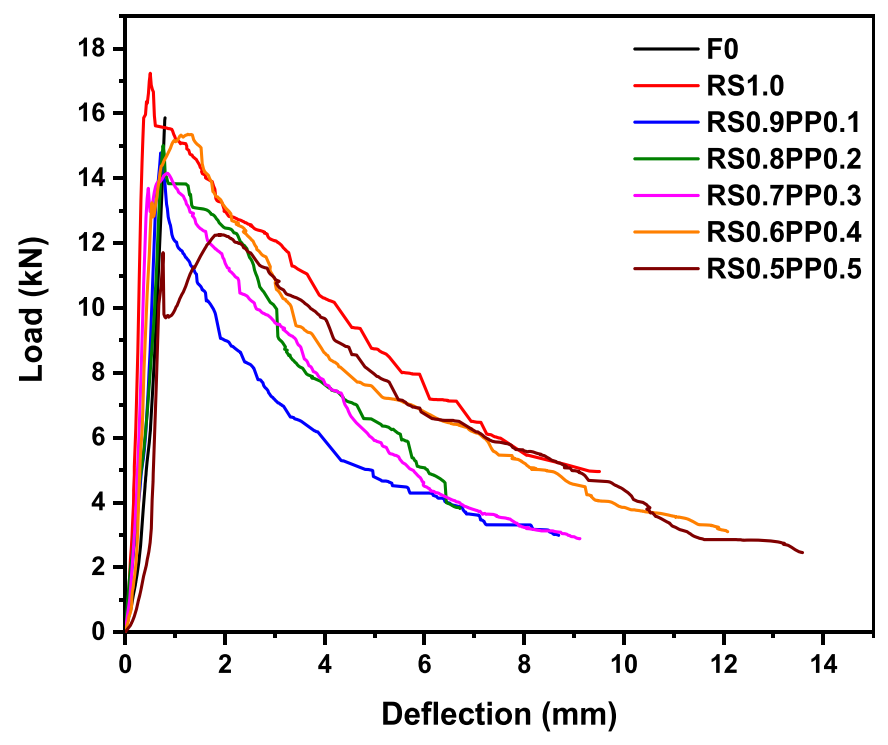

Fig. 9. Load-deflection curves of all mixtures.

at the continuously opening crack still contributed to the enhanced energy absorption (Halvaei et al., 2015; Ranjbar and Zhang, 2020). Splitting tensile strength and flexural strength are commonly used to indirectly evaluate the tensile strength of concrete. Thus, considering the indirect tensile strength of FRC, the upper limit of PPF content $\left(V_{f}\right)$ in hybrid fibre reinforcement is regarded as $0.2 \%$ as adding such dosage improved the splitting tensile strength of plain concrete matrix by about $15.7 \%$ and did not lead to pronounced negative effect on the flexural strength (i.e. no more than $0.6 \%$ reduction). Nevertheless, a relatively large deviation in flexural strength was identified for RS0.7PP0.3 and RS0.6PP0.4, respectively (see Fig. 10), while Grzymski et al. (2019) observed around 25\% variation regarding the mechanical properties of individual RTSF (i.e. unstable performance observed in concrete reinforced with RTSF). This can be ascribed to the irregular geometry and partial damage of RTSF after the recycling process (i.e. mechanical recycling), where the RTSFs are mainly recycled through mechanical shredding or cryogenic process (Liew and Akbar, 2020; Skarżyński

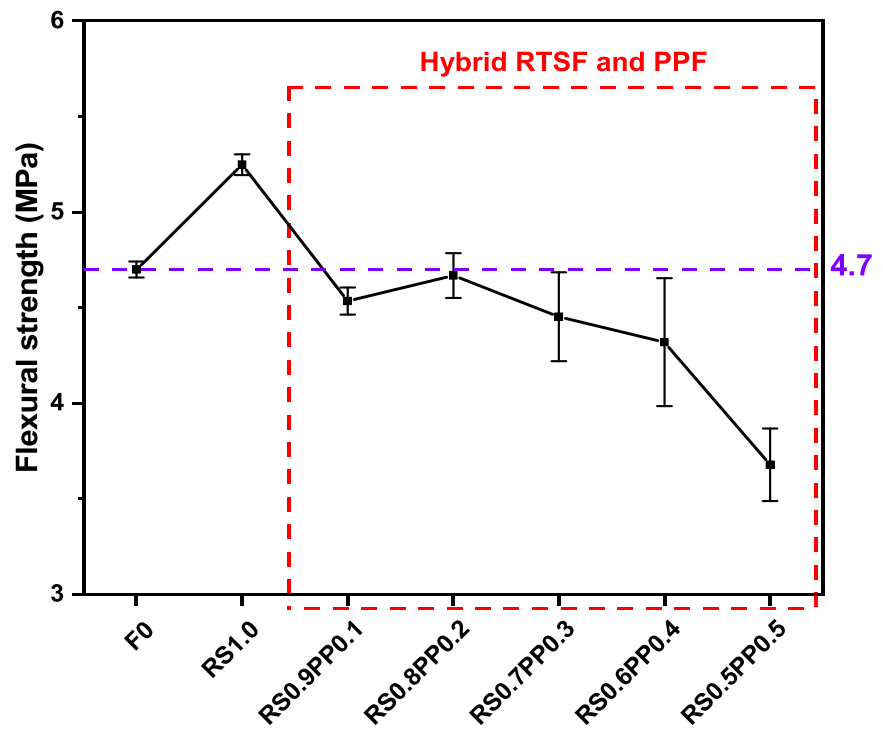

Fig. 10. Effect of fibres on flexural strength of concrete. 
and Suchorzewski, 2018). The damaged or non-uniform RTSF may negatively influence the performance of FRC due to the increased shear resistance, reduced anchorage at the ends and partially corroded section (Caggiano et al., 2017; Grzymski et al., 2019; Hu et al., 2018; Skarżyński and Suchorzewski, 2018). Thus, large deviations can be found in Fig. 10 as the performance of individual RTSF was not consistent within a concrete mixture. Moreover, a high dosage of PPF can also affect the integrity of the whole composite (see Section 3.1).

Regarding the post-cracking performance, deflection-softening features can also be observed in all FRC indicating that the ductility of plain concrete matrix was enhanced through the incorporation of fibres. As seen in Fig. 9, replacing RTSF with PPF from $0.1 \%$ to $0.3 \%$ $\mathrm{V}_{\mathrm{f}}$ led to the ultimate deflection between 6.71 and $9.12 \mathrm{~mm}$, in which these replacement levels did not result in conspicuous enhancement in ultimate deflection. However, with the further addition of PPF (i.e. $0.4 \%$ and $0.5 \% \mathrm{Vf}$ ), the ultimate deflection of FRC was reached up to around $13.58 \mathrm{~mm}$ which was $42.8 \%$ higher than that of RS1.0. This implies that a synergistic effect in post-cracking behaviour could be formed through combining RTSF and PPF in concrete.

To critically understand the difference of crack-evolution between plain concrete mixture and FRC, a non-contact method, DIC analysis, was employed. Fig. 11 presents the typical three zones identified in DIC image for tensile strain analysis (Niu et al., 2019). In zone 1 (uniform zone), the cracks are not formed with the lowest longitudinal strain while the fibre slipping often occurs in the zone 2 , known as fracture process zone. The main crack is located in zone 3 (localization zone) where the fibre-bridging behaviour plays a dominant role in this zone. Since F0 failed very quickly in the elastic stage, only one DIC image corresponding to either point A or B shown in Fig. 8 is presented in Fig. 12. Figs. 13 and 14 illustrate the DIC images indicating the evolution of flexural failure of RS1.0 and RS0.7PP0.3, respectively, in accordance with the key stages shown in Fig. 8. For fair comparison between different mixtures, all DIC images were processed using the same scale and colour. As seen in Fig. 12, red and yellow colours were observed in the strain field showing a clear crack with only one crack tip (i.e. coloured spike) located in the uniform zone. In contrast, with the inclusion of $1.0 \% V_{f}$ of RTSF, no obvious crack tip was identified in the first-cracking point (point $A$ shown in Fig. 8) with the reducing strain (i.e. the blue coloured area), pointing out that very tiny crack was initiated in point $A$ for RS1.0. This further implies that RTSF can better disperse the stress and restrict the crack propagation in the early loading stage (Niu et al., 2019; Onuaguluchi and Banthia, 2018; Skarżyński and Suchorzewski, 2018). Upon reaching the peak load (point B shown in Fig. 8), the main crack extended towards the upper side of the sample with deep green colour shown in the strain field, while the transverse strain around the crack was still relatively

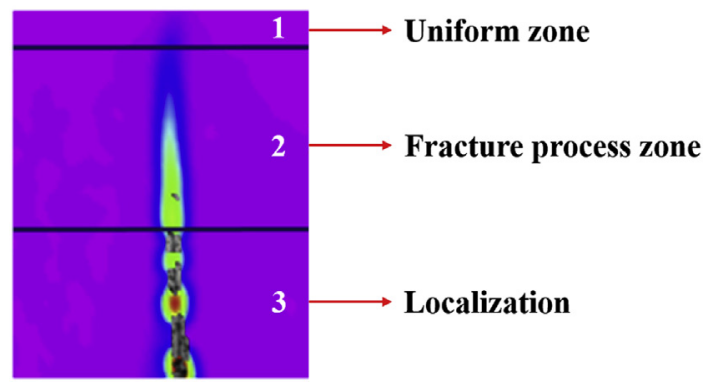

Fig. 11. Three zones identified in DIC image for tensile strain analysis (reproduced from Niu et al. (2019)). lower than that of F0 (see Fig. 12). Fig. 13c, d and e illustrate the points C, D and E shown in Fig. 8, respectively, which correspond to the specified deflection values used to describe the postcracking performance of FRC based on ASTM C1018 (1997). With the increase of flexural loading, curved crack shapes can be clearly observed in points $\mathrm{C}, \mathrm{D}$ and $\mathrm{E}$ with multiple derivative cracks appeared along the main macro crack due to the fibre-birding effect (Li et al., 2018). Thus, the orientation of crack propagation was changed instead of crack localization along a certain path (Ranjbar and Zhang, 2020). Moreover, the crack width was also increased with the rising flexural loading where a large crack width was observed when the specimen completely lost its loadcarrying capacity (point $\mathrm{F}$ in Fig. 8). By contrast, as shown in Fig. 14, similar failure behaviour was noticed for RS0.7PP0.3 whereas the crack propagation was faster than that in RS1.0 (i.e. yellow and red colours appeared in the strain field when the peak load was attained), which supports the previous discussion that PPF was less effective in restraining the growth of crack mainly owing to the weak contact surface and relatively lower stiffness. Nevertheless, more derivative cracks appeared along the main crack or near the cracking tips (see Fig. 14c, d and e), which can be attributed to the smaller fibre spacing of PPF inside the mixture (i.e. shorter length of PPF led to smaller fibre spacing (Wu et al., 2017)) meaning that more fibres are presented around one single crack. Thus, the stress could be dispersed to a wider area resulting in an increasing number of tiny cracks along the main macro crack and the energy absorption is accordingly enhanced. The DIC images at the final failure points of all FRC mixtures are demonstrated in Fig. 15. It can be clearly observed that the main cracks of all FRCs were significantly curved implying that the flexural failure pattern changed into ductile pattern instead of the brittle failure pattern observed in F0 (see Fig. 12). It is worth noting that RS0.8PP0.2 exhibited the most ductile pattern as several crack tips were identified in the strain field (see Fig. 15c), which further suggests that integrating an appropriate dosage of PPF with RTSF could create a synergistic effect on the overall flexural behaviour of FRC.

The synergistic effect of fibre bridging in FRC containing hybrid RTSF and PPF can also be found in Fig. 16, which indicates that numerous PPFs bridged the cracking surface mainly due to the lower fibre spacing between each PPF. Fig. 17 offers a schematic diagram to explain the main fibre bridging mechanism of concrete reinforced with hybrid fibres under flexural loading: At the beginning of loading, several internal micro or macro cracks appear due to the intrinsic defects and shrinkage while the external main crack is not formed. Meanwhile, randomly distributed fibres could bridge the crack relieving the stress from the matrix. However, PPF can only resist the growth of smaller micro-crack because of its weaker contact with the matrix and lower tensile properties (i.e. smaller pull-out load). As the loading increases, the main crack gradually propagates, and the fibre bridging plays an essential role in improving the flexural behaviour. Fibre slipping and de-bonding may occur when the interaction between fibre and matrix is low (i.e. may arise at the interface of PPF and matrix). Fibre rupture arises when the accumulated stress overcomes the fibre reinforcement limit when the fibre is strongly adhered to the matrix (i.e. may be observed at the interface of RTSF and matrix). Both mechanisms can lead to the enhanced post-cracking performance especially energy absorption capacity, but the amount of energy absorption is affected by various factors such as fibre number and fibre spacing around a certain crack. To sum up, the overall fibre behaviour greatly contributes to the enhanced flexural behaviour of FRC, where the enhancement is more pronounced when more fibres are aligned perpendicular to the loading direction (Zhong et al., 2019). 


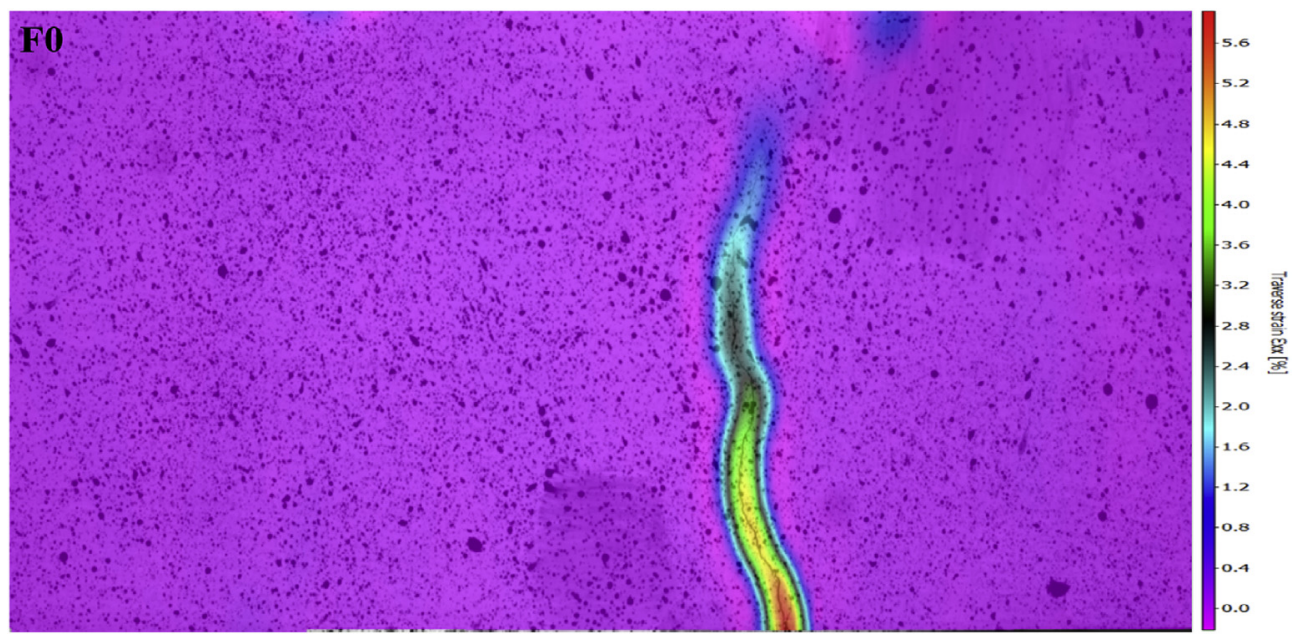

Fig. 12. DIC image at final failure point of F0 corresponding to point A or B in Fig. 8.
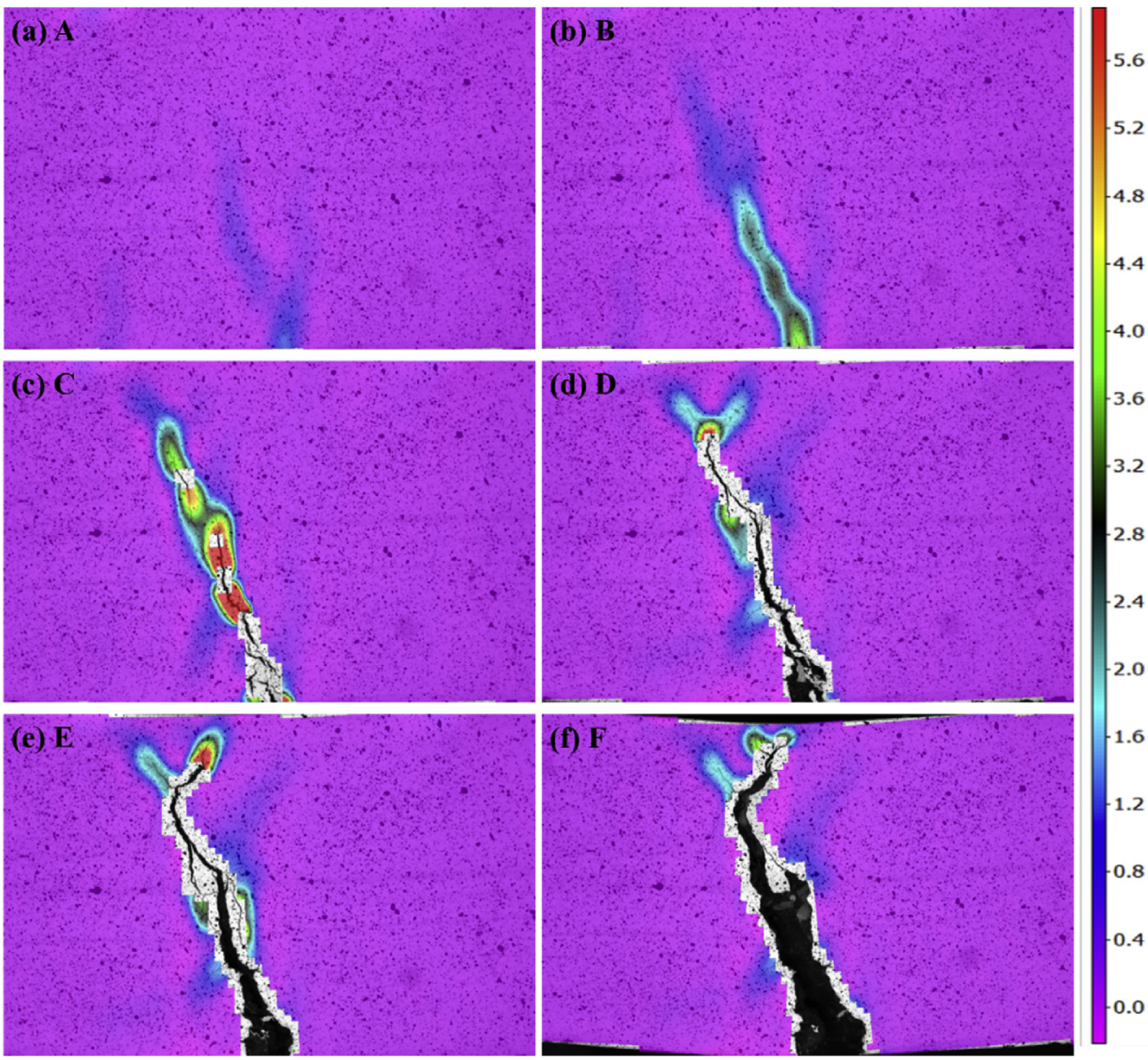

Fig. 13. DIC images showing the evolution of flexural failure for RS1.0 corresponding to key stages in Fig. 8.

\subsubsection{Flexural toughness and residual strength factor}

Toughness indices $\left(I_{5}, I_{10}\right.$ and $\left.I_{20}\right)$ calculated based on ASTM C1018 (1997) were used to evaluate the flexural behaviour of FRC after the first-peak load. In practice, structure with enough toughness can avoid the sudden failure without any warnings which increases its overall safety. The toughness indices of all FRC mixtures are listed in Table 4. No toughness indices were reported for F0 as it failed very quickly within the elastic region. As seen in Table 4, incorporating hybrid RTSF and PPF into concrete changed its toughness indices as compared with RS1.0, whereas no consistent trend can be found when the fibre dosage altered. Generally, except RS0.9PP0.1, increasing PPF content (i.e. decreasing RTSF content) resulted in enhanced toughness indices. Among them, RS0.5PP0.5 attained the highest $I_{5}, I_{10}$ and $I_{20}$ of 7.09, 13.95 and 

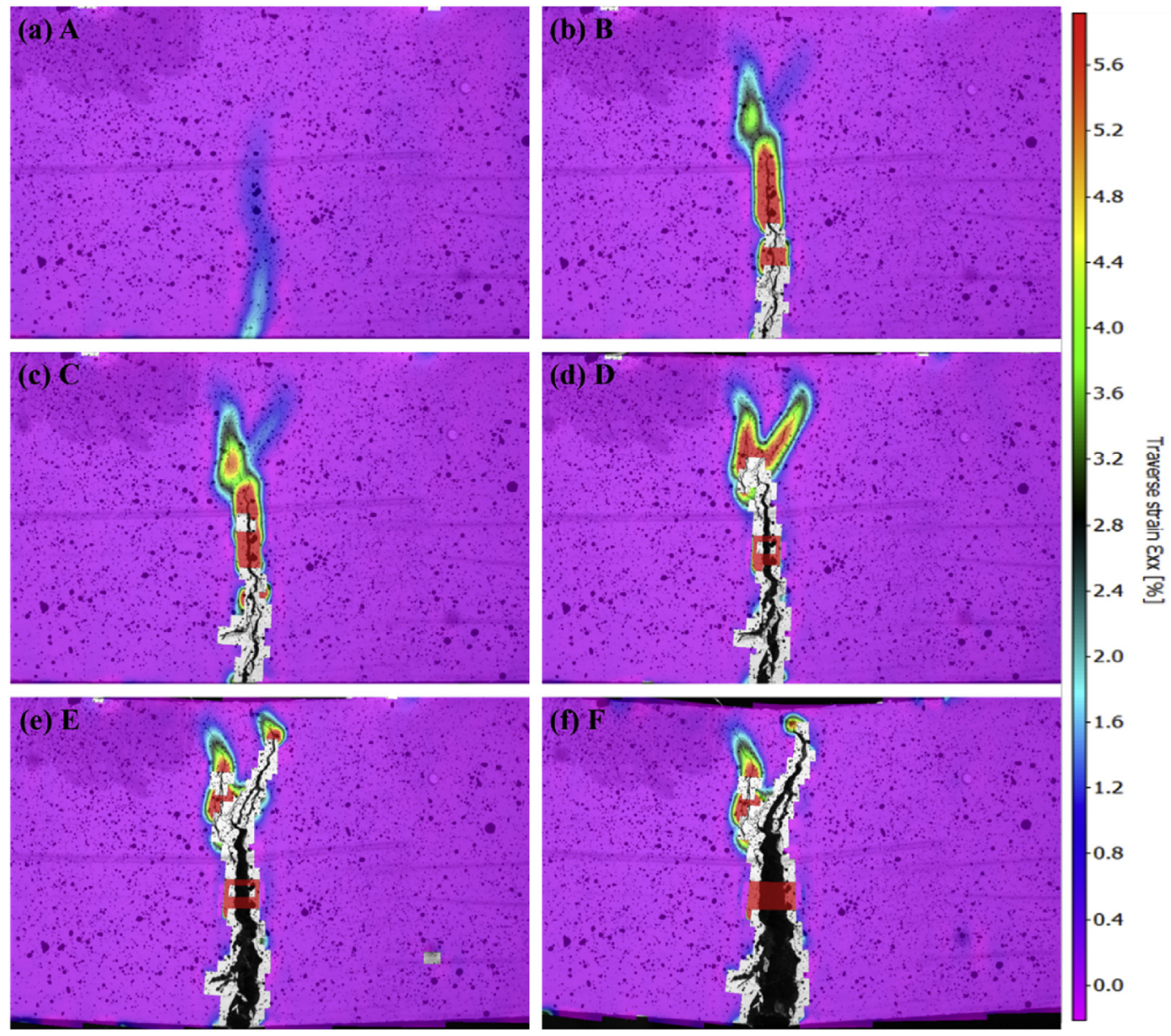

Fig. 14. DIC images showing the evolution of flexural failure for RS0.7PP0.3 corresponding to key stages in Fig. 8.

23.37, respectively, which was around $1.44,3.09$ and 3.42 higher than that of RS1.0. Previous studies (Caggiano et al., 2017; Martinelli et al., 2015) reported that increasing RTSF content led to reduced toughness indices primarily due to the inconsistent efficiency of each RTSF (after recycling process) within a concrete mixture (see Section 3.3.1) leading to unstable performance between each specimen and large deviation. Moreover, as mentioned before, RTSF may experience breakage or rupture during the fibre pull-out process due to its higher bonding strength with the cementitious matrix or its irregular geometry (Frazão et al., 2019). Thus, the ultimate deflection or area under the load-deflection curve would be lower resulting in reduced toughness properties (Halvaei et al., 2015). If RTSF and PPF can be well orientated within the mixture, a positive synergy can be formed, which increases the toughening mechanism of FRC.

Fig. 18 illustrates the effect of fibres on the residual strength factors of concrete where these factors can be considered as the important measures of ductility (Zhong et al., 2019). A similar phenomenon can be noticed that there was no consistent trend in terms of residual strength factors when the PPF dosage increased from $0.1 \%$ to $0.5 \% \mathrm{~V}_{\mathrm{f}}$. As seen in Fig. 18, RS0.5PP0.5 also achieved the highest $R_{5,10}$ and $R_{10,20}$ of approximately 137.3 and 94.2 , respectively, which outperformed RS1.0 with $R_{5,10}$ and $R_{10,20}$ of 104.2 and 90.9, respectively. In addition, it can be observed that RS1.0, RS0.7PP0.3 and RS0.5PP0.5 all had the $R_{5,10}$ of over 100 meaning that these mixtures can be regarded as perfectly plastic materials (Fu et al., 2019). The observed inconsistent trend and large variation can be also ascribed to the reasons explained in toughness indices.

\subsection{Drying shrinkage}

Drying shrinkage represents the time-dependent volume change of hardened cementitious materials due to the water loss within a drying environmental condition with $\mathrm{RH}$ of less than $95 \%$ (Rezvani et al., 2019). Drying shrinkage is regarded as the main reason causing the formation of early-age cracking in concrete (Yousefieh et al., 2017). Fig. 19 shows the effect of fibres on the drying shrinkage of concrete. To clearly observe the trend of each mixture, standard deviation was not plotted where the highest deviation of F0, RS1.0, RS0.9PP0.1, RS0.8PP0.2, RS0.7PP0.3, RS0.6PP0.4 and RS0.5PP0.5 was 8.7\%, 10.8\%, 19.9\%, 7.1\%, 6.6\%, 12.5 and $12.4 \%$, respectively. In general, as seen in Fig. 19, the incorporation of fibres reduced the drying shrinkage independent of fibre reinforcement type. All mixtures exhibited large drying shrinkage at the early age between 140.4 and $350.9 \mu \varepsilon$, while the shrinkage strain rate decreased with the increase of curing age. It is worth pointing out that RS1.0 consistently showed the lowest drying shrinkage which achieved around $959.1 \mu \varepsilon$ at 28 d, i.e. about $18.8 \%$ lower than that of F0. This finding is consistent with Al-musawi et al. (2019) that RTSF with high tensile strength can bridge the crack induced by shrinkage, which transfers the stress leading to the enhancement in tensile strength. Regarding the hybrid fibre combination, increasing the PPF content did not induce a consistent trend in reducing the drying shrinkage. Afroughsabet et al. (2018) found similar phenomenon in concrete reinforced with MSF and PPF. Apart from RS1.0, RS0.9PP0.1, RS0.7PP0.3 and RS0.5PP0.5 presented comparable behaviour in drying shrinkage, where the 

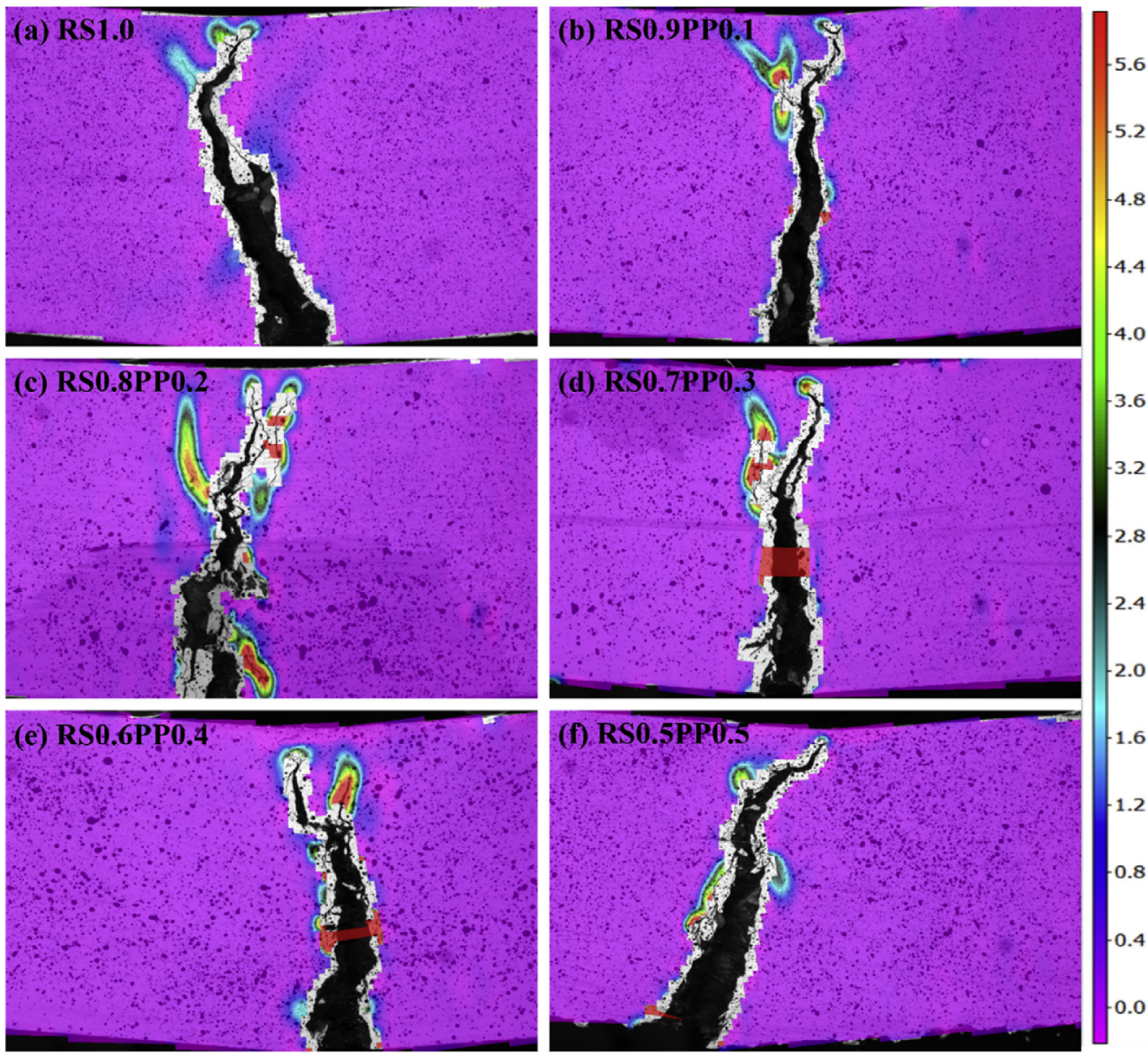

Fig. 15. DIC images at final failure points of all mixtures corresponding to point $\mathrm{F}$ in Fig. 8.

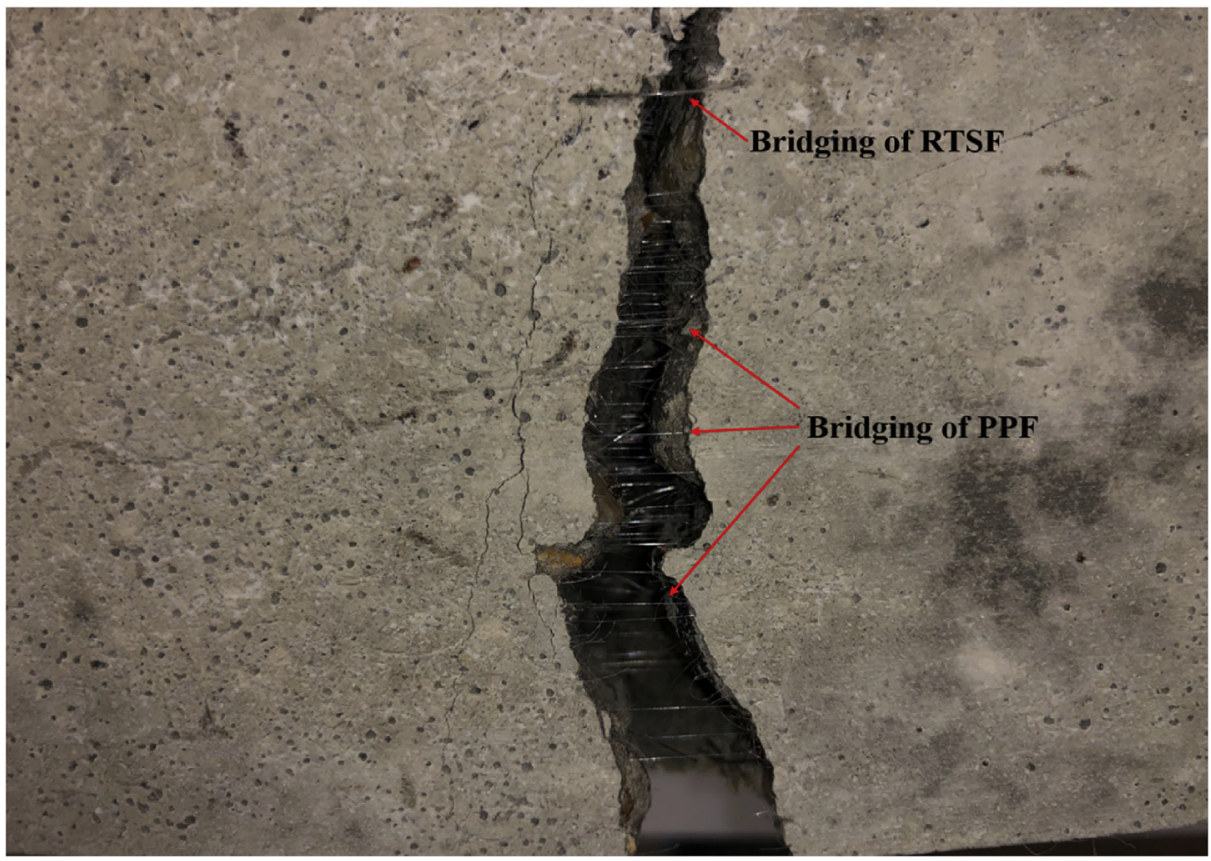

Fig. 16. Picture showing the fibre bridging in fibre reinforced concrete. 


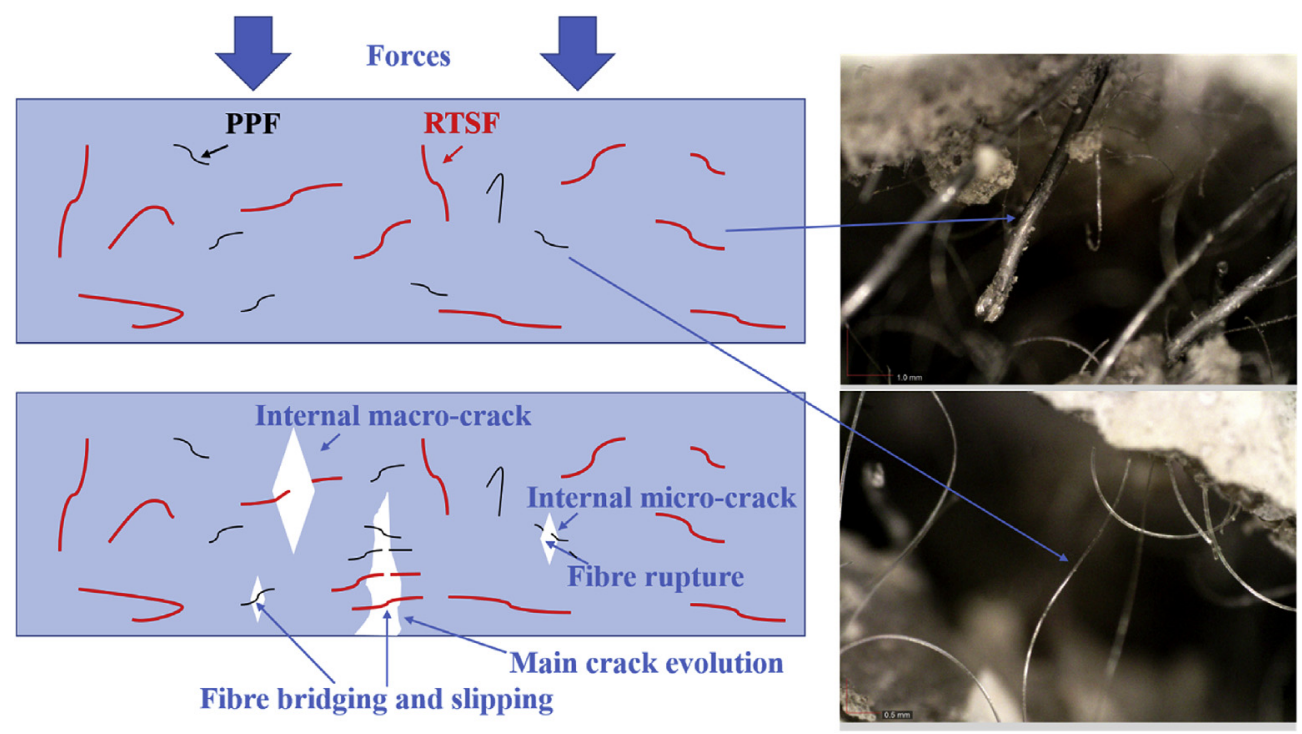

Fig. 17. Fibre bridging mechanism of fibre reinforced concrete under flexural loading.

Table 4

Toughness indices of fibre reinforced concrete.

\begin{tabular}{|c|c|c|c|c|c|c|}
\hline Mixture & $I_{5}$ & Standard deviation & $I_{10}$ & Standard deviation & $I_{20}$ & Standard deviation \\
\hline RS1.0 & 5.65 & 0.35 & 10.86 & 0.57 & 19.95 & 0.89 \\
\hline RS0.9PP0.1 & 5.48 & 0.04 & 8.79 & 0.53 & 13.31 & 0.87 \\
\hline RS0.8PP0.2 & 6.19 & 0.33 & 10.72 & 0.32 & 15.70 & 0.31 \\
\hline RS0.7PP0.3 & 7.06 & 0.89 & 13.82 & 1.99 & 22.99 & 3.24 \\
\hline RS0.6PP0.4 & 5.82 & 0.02 & 10.46 & 0.06 & 15.99 & 0.76 \\
\hline RS0.5PP0.5 & 7.09 & 0.57 & 13.95 & 1.51 & 23.37 & 2.37 \\
\hline
\end{tabular}

corresponding 28 -d drying shrinkage was $12.9 \%, 10.9 \%$ and $10.9 \%$ smaller than that of F0. The inconsistent trend after adding PPF can be also associated with the fibre orientation and poor compaction of the whole composite (Ranjbar and Zhang, 2020): the more fibres align perpendicular to the shrinkage-induced crack, the lower the drying shrinkage.

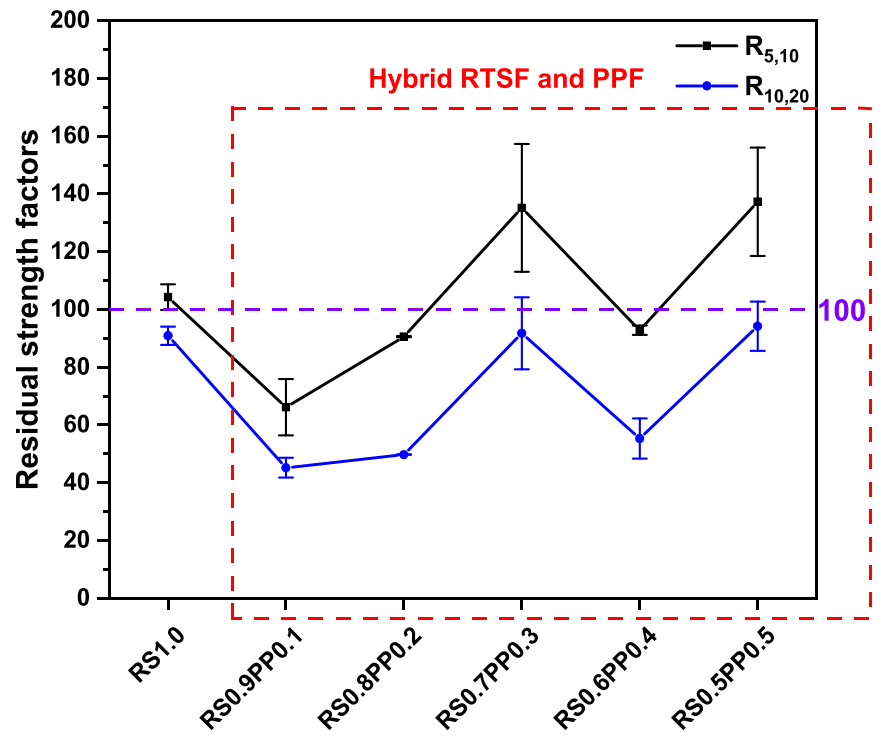

Fig. 18. Effect of fibres on residual strength factors of concrete.

\subsection{Rapid chloride migration coefficient}

Chloride diffusion or migration coefficient is an important property of FRC related to the long-term durability of reinforced concrete structures, which can be affected by various factors such as volume fraction, size distribution and connectivity of pores and microcracks within FRC (Teng et al., 2018). Fig. 20 illustrates the

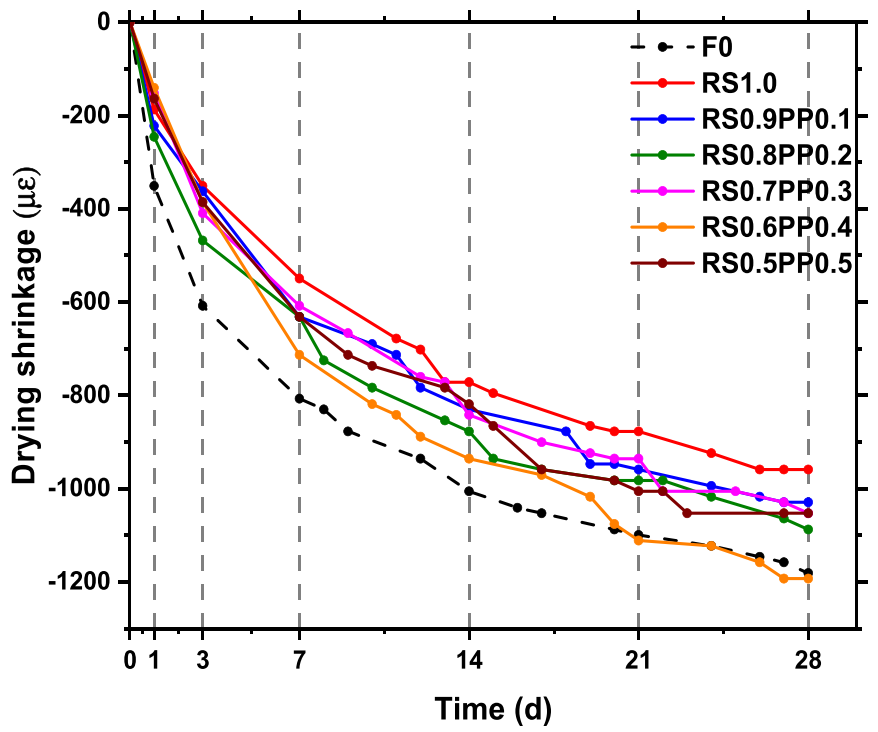

Fig. 19. Effect of fibres on drying shrinkage of concrete. 


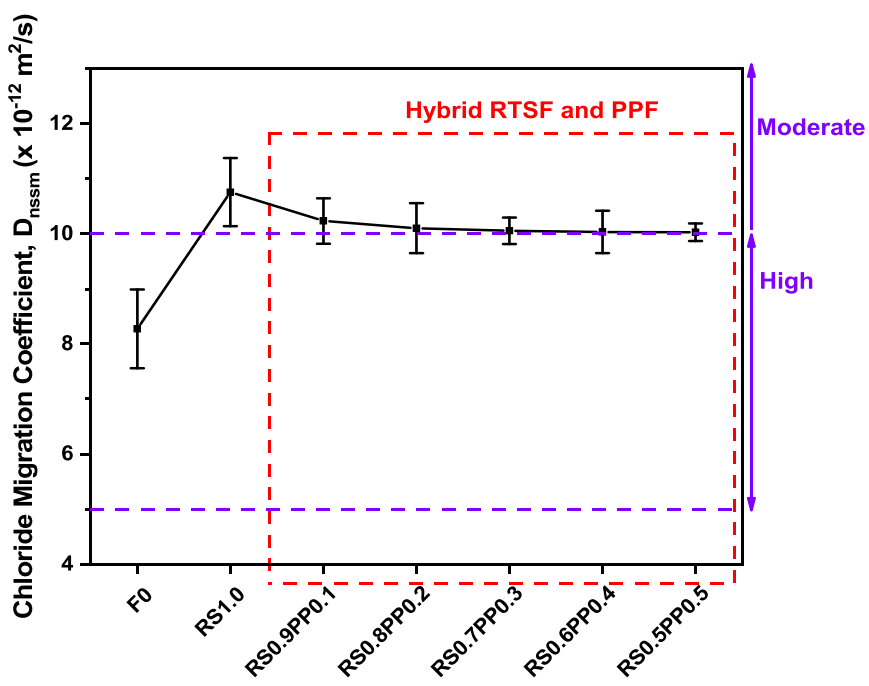

Fig. 20. Effect of fibres on chloride migration coefficient of concrete.

effect of fibres on the chloride migration coefficient $\left(D_{n s s m}\right)$ at $28 \mathrm{~d}$, which was classified into different resistance levels according to Table 5. As seen in Fig. 20, the $D_{n s s m}$ of mixture without fibre reinforcement (F0) was around $8.27 \times 10^{-12} \mathrm{~m}^{2} / \mathrm{s}$ which can be classified as 'high' in terms of the resistance to chloride penetration. However, the incorporation of fibres increased the $D_{\text {nssm }}$ of concrete, which was in the range of $10.03 \times 10^{-12}$ to $10.76 \times 10^{-12} \mathrm{~m}^{2}$ / s. RS1.0 exhibited the highest $D_{\text {nssm }}$ which was in agreement with previous studies (Song et al., 2018; Teng et al., 2018) that the high conductivity of SFs significantly contributed to the increment of $D_{n s s m}$, as RCM test is conducted based on the passing of electric current within the concrete. Adding more SFs would increase the number of connected fibres and accordingly the current through concrete would be increased as well as $D_{n s s m}$. On the other hand, replacing RTSF by PPF gradually reduced the $D_{n s s m}$. Adding PPF content from $0.1 \%$ to $0.5 \% \mathrm{~V}_{\mathrm{f}}$ decreased the $D_{n s s m}$ by around $4.9 \%-$ $6.8 \%$ compared to RS1.0, which can be ascribed to the decreased inner conductivity of pores within the concrete. A similar observation was reported by Afroughsabet et al. (2018). In addition, the resistance of chloride migration can be classified as 'high' when the PPF content in hybrid fibre combination ranges from $0.3 \%$ to $0.5 \% V_{f}$.

\section{Conclusions}

This study investigated the engineering properties of concrete reinforced with recycled tyre steel fibre (RTSF) and polypropylene fibre (PPF) to evaluate the feasibility of using RTSF as primary fibre in hybrid fibre reinforced concrete with a total fibre content of $1.0 \%$ $\mathrm{V}_{\mathrm{f}}$. Based on the experimental results, the conclusions can be drawn as follows:

- Regardless of fibre reinforcement type (mono or hybrid), the incorporation of fibres reduced the workability of concrete. RTSF resulted in more significant effect on workability as replacing RTSF with PPF from $0.1 \%$ to $0.5 \% V_{f}$ induced obvious improvement in workability.

- The compressive strengths were found to be slightly enhanced by adding RTSF only in concrete while combining RTSF with PPF in concrete resulted in a reduction. Considering the splitting tensile strength, $0.2 \% V_{f}$ was the upper limit for PPF content in hybrid fibre reinforcement as further addition of PPF decreased the splitting tensile strength.

- RTSF was more effective in improving the flexural strength of concrete (i.e. increased by $116.8 \%$ when adding RTSF only), whereas replacing RTSF with PPF did not induce pronounced change in flexural strength. Nevertheless, RS0.5PP0.5 significantly improved the post-cracking behaviour of concrete in terms of toughness indices and residual strength factors.

- Digital image correlation image analysis indicated that the incorporation of fibres into concrete delayed the crack propagation via fibre-bridging mechanism and more derivative cracks along the main crack were observed when combining RTSF with PPF in concrete primarily due to the smaller fibre spacing of PPF.

- The incorporation of fibres significantly reduced the drying shrinkage of concrete where RTSF was the most effective in restraining the drying shrinkage. On the other hand, the resistance to chloride migration was improved when increasing the PPF content in hybrid fibre reinforcement, in which the chloride migration coefficient of hybrid fibre reinforced concrete was $4.9 \%-6.8 \%$ lower than that of mono fibre reinforced concrete.

The effective usage of RTSF in concrete can improve the sustainability of the construction industry via mitigating the environmental impact and natural resource shortage caused by landfilled solid waste tyre and production of manufactured steel fibre (MSF). The incorporation of RTSF into concrete led to the reduced ductility and corrosion resistance in comparison with the use of MSF in concrete. Thus, this study discussed the use of RTSF as primary fibre along with synthetic PPF to enhance the engineering properties of concrete under controlled total fibre content $\left(1.0 \% V_{f}\right)$. The results suggest that hybrid RTSF and PPF can improve the energy absorption capacity and chloride migration resistance while maintaining the benefits caused by RTSF. The suitable PPF content was regarded as $0.1 \%-0.3 \% \mathrm{~V}_{\mathrm{f}}$. However, the potentially damaged RTSF after the recycling process and its irregular geometry may lead to unstable performance of the resultant composite (e.g. large deviation). Therefore, for certain applications, the dimension and dosage of RTSF should be carefully considered during the mix design.

\section{Declaration of competing interest}

The authors declare that there is no conflict of interest.

\section{CRediT authorship contribution statement}

Hui Zhong: Conceptualization, Methodology, Investigation, Visualization, Writing - original draft. Mingzhong Zhang: Supervision, Writing - review \& editing.

Table 5

Classification of resistance to chloride migration (Afroughsabet et al., 2018).

\begin{tabular}{ll}
\hline Chloride migration coefficient, $\mathrm{D}_{\mathrm{nssm}}\left(\times 10^{-12} \mathrm{~m}^{2} / \mathrm{s}\right)$ & Classification of resistance to chloride migration \\
\hline$>15$ & Low \\
$10-15$ & Moderate \\
$5-10$ & High \\
$2.5-5$ & Very high \\
$<2.5$ & Extremely high \\
\hline
\end{tabular}




\section{Acknowledgement}

The authors gratefully acknowledge the financial support from the Engineering and Physical Sciences Research Council (EPSRC), United Kingdom under Grant Nos. EP/R041504/1 and EP/N509577/ 1 (project reference: 1836739). The financial support provided by University College London (UCL) and China Scholarship Council (CSC) to the first author is gratefully acknowledged. The authors would like to thank Mr. Warren Gaynor, Dr. Shi Shi, and Mr. Raman Mangabhai for their help with experiments.

\section{References}

Afroughsabet, V., Biolzi, L., Monteiro, P.J.M., 2018. The effect of steel and polypropylene fibers on the chloride diffusivity and drying shrinkage of highstrength concrete. Compos. B Eng. 139, 84-96.

Afroughsabet, V., Ozbakkaloglu, T., 2015. Mechanical and durability properties of high-strength concrete containing steel and polypropylene fibers. Construct. Build. Mater. 94, 73-82.

Ahmadi, M., Farzin, S., Hassani, A., Motamedi, M., 2017. Mechanical properties of the concrete containing recycled fibers and aggregates. Construct. Build. Mater. 144, 392-398.

Aiello, M.A., Leuzzi, F., Centonze, G., Maffezzoli, A., 2009. Use of steel fibres recovered from waste tyres as reinforcement in concrete: pull-out behaviour, compressive and flexural strength. Waste Manag. 29 (6), 1960-1970.

Al-musawi, H., Figueiredo, F.P., Guadagnini, M., Pilakoutas, K., 2019. Shrinkage properties of plain and recycled steel-fibre-reinforced rapid hardening mortars for repairs. Construct. Build. Mater. 197, 369-384.

Almusallam, T., Ibrahim, S.M., Al-Salloum, Y., Abadel, A., Abbas, H., 2016. Analytical and experimental investigations on the fracture behavior of hybrid fiber reinforced concrete. Cement Concr. Compos. 74, 201-217.

ASTM 143-15a, 2015. Standard Test Method for Slump of Hydraulic-Cement Concrete. ASTM International, West Conshohocken, PA.

ASTM C490, 2017. Standard Practice for Use of Apparatus for the Determination of Length Change of Hardened Cement Paste, Mortar, and Concrete. ASTM International, West Conshohocken, PA.

ASTM C496, 2011. Standard Test Method for Splitting Tensile Strength of Cylindrical Concrete Specimens. ASTM International, West Conshohocken, PA.

ASTM C1018, 1997. Standard Test Method for Flexural Toughness and First-Crack Strength of Fiber-Reinforced Concrete (Using Beam with Third-Point Loading). ASTM International, West Conshohocken, PA, United States.

Baricevic, A., Bjegovic, D., Skazlic, M., 2017. Hybrid fiber-reinforced concrete with unsorted recycled-tire steel fibers. J. Mater. Civ. Eng. 29 (6), 06017005.

Bjegovic, D., Baricevic, A., Lakusic, S., Damjanovic, D., Duvnjak, I., 2014. Positive interaction of industrial and recycled steel fibres in fibre reinforced concrete. J. Civ. Eng. Manag. 19, S50-S60.

BS EN 12390-3, 2009. Testing Hardened Concrete Part 3: Compressive Strength of Test Specimens. BSI Standards Publication.

Caggiano, A., Folino, P., Lima, C., Martinelli, E., Pepe, M., 2017. On the mechanical response of hybrid fiber reinforced concrete with recycled and industrial steel fibers. Construct. Build. Mater. 147, 286-295.

Caggiano, A., Gambarelli, S., Martinelli, E., Nisticò, N., Pepe, M., 2016. Experimental characterization of the post-cracking response in hybrid steel/polypropylene fiber-reinforced concrete. Construct. Build. Mater. 125, 1035-1043.

Centonze, G., Leone, M., Aiello, M.A., 2012. Steel fibers from waste tires as reinforcement in concrete: a mechanical characterization. Construct. Build. Mater. 36, 46-57.

de Alencar Monteiro, V.M., Lima, L.R., de Andrade Silva, F., 2018. On the mechanical behavior of polypropylene, steel and hybrid fiber reinforced self-consolidating concrete. Construct. Build. Mater. 188, 280-291.

Feng, J., Gao, X., Li, J., Dong, H., Yao, W., Wang, X., Sun, W., 2019. Influence of fiber mixture on impact response of ultra-high-performance hybrid fiber reinforced cementitious composite. Compos. B Eng. 163, 487-496.

Frazão, C., Díaz, B., Barros, J., Bogas, J.A., Toptan, F., 2019. An experimental study on the corrosion susceptibility of recycled steel fiber reinforced concrete. Cement Concr. Compos. 96, 138-153.

Fu, C., Ye, H., Wang, K., Zhu, K., He, C., 2019. Evolution of mechanical properties of steel fiber-reinforced rubberized concrete (FR-RC). Compos. B Eng. 160, $158-166$.

Gigli, S., Landi, D., Germani, M., 2019. Cost-benefit analysis of a circular economy project: a study on a recycling system for end-of-life tyres. J. Clean. Prod. 229, 680-694.

Grünewald, S., 2012. 9 - fibre reinforcement and the rheology of concrete. In: Roussel, N. (Ed.), Understanding the Rheology of Concrete. Woodhead Publishing, pp. 229-256.

Grzymski, F., Musiał, M., Trapko, T., 2019. Mechanical properties of fibre reinforced concrete with recycled fibres. Construct. Build. Mater. 198, 323-331.

Halvaei, M., Jamshidi, M., Pakravan, H.R., Latifi, M., 2015. Interfacial bonding of fine aggregate concrete to low modulus fibers. Construct. Build. Mater. 95, 117-123.

Hu, H., Papastergiou, P., Angelakopoulos, H., Guadagnini, M., Pilakoutas, K., 2018. Mechanical properties of SFRC using blended manufactured and recycled tyre steel fibres. Construct. Build. Mater. 163, 376-389.

Leone, M., Centonze, G., Colonna, D., Micelli, F., Aiello, M.A., 2018. Fiber-reinforced concrete with low content of recycled steel fiber: shear behaviour. Construct. Build. Mater. 161, 141-155.

Li, B., Chi, Y., Xu, L., Shi, Y., Li, C., 2018. Experimental investigation on the flexural behavior of steel-polypropylene hybrid fiber reinforced concrete. Construct. Build. Mater. 191, 80-94.

Li, Y., Pimienta, P., Pinoteau, N., Tan, K.H., 2019a. Effect of aggregate size and in clusion of polypropylene and steel fibers on explosive spalling and pore pressure in ultra-high-performance concrete (UHPC) at elevated temperature. Cement Concr. Compos. 99, 62-71.

Li, Y., Tan, K.H., Yang, E.-H., 2019b. Synergistic effects of hybrid polypropylene and steel fibers on explosive spalling prevention of ultra-high performance concrete at elevated temperature. Cement Concr. Compos. 96, 174-181.

Liew, K.M., Akbar, A., 2020. The recent progress of recycled steel fiber reinforced concrete. Construct. Build. Mater. 232, 117232.

Martinelli, E., Caggiano, A., Xargay, H., 2015. An experimental study on the postcracking behaviour of hybrid industrial/recycled steel fibre-reinforced concrete. Construct. Build. Mater. 94, 290-298.

Mastali, M., Dalvand, A., Sattarifard, A.R., Abdollahnejad, Z., Illikainen, M., 2018a. Characterization and optimization of hardened properties of self-consolidating concrete incorporating recycled steel, industrial steel, polypropylene and hybrid fibers. Compos. B Eng. 151, 186-200.

Mastali, M., Dalvand, A., Sattarifard, A.R., Illikainen, M., 2018b. Development of ecoefficient and cost-effective reinforced self-consolidation concretes with hybrid industrial/recycled steel fibers. Construct. Build. Mater. 166, 214-226.

Mazzoli, A., Monosi, S., Plescia, E.S., 2015. Evaluation of the early-age-shrinkage of Fiber Reinforced Concrete (FRC) using image analysis methods. Construct. Build Mater. 101, 596-601.

Niu, Y. Huang, H. Zhang, J., Jin, W. Wei, J., Yu, O, 2019. Development of the strain field along the crack in ultra-high-performance fiber-reinforced concrete (UHPFRC) under bending by digital image correlation technique. Cement Concr. Res. 125, 105821.

NT BUILD 492, 1999. Concrete, Mortar and Cement-Based Repair Materials: Chloride Migration Coefficient from Non-steady-state Migration Experiments. Nordtest Method, Finland.

Onuaguluchi, O., Banthia, N., 2018. Scrap tire steel fiber as a substitute for commercial steel fiber in cement mortar: engineering properties and cost-benefit analyses. Resour. Conserv. Recycl. 134, 248-256.

Pakravan, H.R., Latifi, M., Jamshidi, M., 2017. Hybrid short fiber reinforcement system in concrete: a review. Construct. Build. Mater. 142, 280-294.

Pakravan, H.R., Ozbakkaloglu, T., 2019. Synthetic fibers for cementitious composites: a critical and in-depth review of recent advances. Construct. Build. Mater. 207, $491-518$.

Qian, C.X., Stroeven, P., 2000. Development of hybrid polypropylene-steel fibrereinforced concrete. Cement Concr. Res. 30, 63-69.

Ramarad, S., Khalid, M., Ratnam, C.T., Chuah, A.L., Rashmi, W., 2015. Waste tire rubber in polymer blends: a review on the evolution, properties and future. Prog. Mater. Sci. 72, 100-140.

Ranjbar, N., Talebian, S., Mehrali, M., Kuenzel, C., Cornelis Metselaar, H.S. Jumaat, M.Z., 2016. Mechanisms of interfacial bond in steel and polypropylene fiber reinforced geopolymer composites. Compos. Sci. Technol. 122, 73-81.

Ranjbar, N., Zhang, M., 2020. Fiber-reinforced geopolymer composites: a review. Cement Concr. Compos. 107, 103498.

Rezvani, M., Proske, T., Graubner, C.-A., 2019. Modelling the drying shrinkage of concrete made with limestone-rich cements. Cement Concr. Res. 115, 160-175.

Sengul, O., 2016. Mechanical behavior of concretes containing waste steel fibers recovered from scrap tires. Construct. Build. Mater. 122, 649-658.

Sivakumar, A., Santhanam, M., 2007. Mechanical properties of high strength concrete reinforced with metallic and non-metallic fibres. Cement Concr. Compos. 29 (8), 603-608.

Skarżyński, Ł., Suchorzewski, J., 2018. Mechanical and fracture properties of concrete reinforced with recycled and industrial steel fibers using Digital Image Correlation technique and X-ray micro computed tomography. Construct. Build. Mater. 183, 283-299.

Song, Q., Yu, R., Shui, Z., Rao, S., Wang, X., Sun, M., Jiang, C., 2018. Steel fibre content and interconnection induced electrochemical corrosion of Ultra-High Performance Fibre Reinforced Concrete (UHPFRC). Cement Concr. Compos. 94, $191-200$.

Suhaendi, S.L., Horiguchi, T., 2006. Effect of short fibers on residual permeability and mechanical properties of hybrid fibre reinforced high strength concrete after heat exposition. Cement Concr. Res. 36 (9), 1672-1678.

Sun, W., Chen, H., Luo, X., Qian, H., 2001. The effect of hybrid fibers and expansive agent on the shrinkage and permeability of high-performance concrete. Cement Concr. Res. 31 (4), 595-601.

Teng, S., Afroughsabet, V., Ostertag, C.P., 2018. Flexural behavior and durability properties of high performance hybrid-fiber-reinforced concrete. Construct. Build. Mater. 182, 504-515.

Thomas, B.S., Gupta, R.C., 2016. A comprehensive review on the applications of waste tire rubber in cement concrete. Renew. Sustain. Energy Rev. 54, 1323-1333.

Wang, J., Dai, Q., Si, R., Guo, S., 2019. Mechanical, durability, and microstructural properties of macro synthetic polypropylene (PP) fiber-reinforced rubber concrete. J. Clean. Prod. 234, 1351-1364.

Wu, Z., Shi, C., He, W., Wang, D., 2017. Static and dynamic compressive properties of 
ultra-high performance concrete (UHPC) with hybrid steel fiber reinforcements. Cement Concr. Compos. 79, 148-157.

Yao, W., Li, J., Wu, K., 2003. Mechanical properties of hybrid fiber-reinforced concrete at low fiber volume fraction. Cement Concr. Res. 33 (1), 27-30.

Yap, S.P., Alengaram, U.J., Jumaat, M.Z., 2013. Enhancement of mechanical properties in polypropylene- and nylon-fibre reinforced oil palm shell concrete. Mater. Des. 49, 1034-1041.

Yermak, N., Pliya, P., Beaucour, A.L., Simon, A., Noumowé, A., 2017. Influence of steel and/or polypropylene fibres on the behaviour of concrete at high temperature: spalling, transfer and mechanical properties. Construct. Build. Mater. 132
$240-250$.

Yousefieh, N., Joshaghani, A., Hajibandeh, E., Shekarchi, M., 2017. Influence of fibers on drying shrinkage in restrained concrete. Construct. Build. Mater. 148, $833-845$.

Zamanzadeh, Z., Lourenço, L., Barros, J., 2015. Recycled steel fibre reinforced concrete failing in bending and in shear. Construct. Build. Mater. 85, 195-207.

Zhong, H., Poon, E.W., Chen, K., Zhang, M., 2019. Engineering properties of crumb rubber alkali-activated mortar reinforced with recycled steel fibres. J. Clean. Prod. 238, 117950. 